NBER WORKING PAPER SERIES

\title{
QUANTIFYING THE BENEFITS OF NEW PRODUCTS: THE CASE OF THE MINIVAN
}

\author{
Amil Petrin \\ Working Paper 8227 \\ http://www.nber.org/papers/w8227 \\ NATIONAL BUREAU OF ECONOMIC RESEARCH \\ 1050 Massachusetts Avenue \\ Cambridge, MA 02138 \\ April 2001
}

This research has benefited from discussions with Dan Ackerberg, Steve Berry, Judy Chevalier, Roger Gordon, Gautam Gowrisankaran, Torn Hubbard, Peter Klenow, James Levinsolm, Jeff Mackie-Mason, Aviv Nevo, Ariel Pakes, Sinichi Sakata, Frank Wolak, a very helpful referee, and numerous seminar participants. Financial support from the Alfred P. Sloan Foundation is gratefully acknowledged. The views expressed herein are those of the author and not necessarily those of the National Bureau of Economic Research.

(C) 2001 by Amil Petrin. All rights reserved. Short sections of text, not to exceed two paragraphs, may be quoted without explicit permission provided that full credit, including (C) notice, is given to the source. 
Quantifying the Benefits of New Products: The Case of the Minivan

Amil Petrin

NBER Working Paper No. 8227

April 2001

JEL No. C51, D12, D43, D60, L13, O47

\begin{abstract}
I develop a technique useful for obtaining more precise estimates of demand and supply curves when constrained to market-level data. It augments the estimation routine with data on the average characteristics of consumers that purchase different products. I apply the technique to the automobile market, estimating the economic effects of the minivan introduction. I show that standard approaches yield results that are meaningfully different from those obtained with my extension. I report benefits accruing to both minivan and non-minivan consumers. I complete the welfare picture by measuring the extent of first- mover advantage and of profit cannibalization both initially by the innovator and later by the imitators. My results support a simple economic story where large improvements in consumers' standard of living arise from competition as firms, ignoring the externalities they impose on one another, cannibalize each others profits by continually seeking new goods that give them some temporary market power.
\end{abstract}

Amil Petrin

Graduate School of Business

University of Chicago

1101 E. $58^{\text {th }}$ St.

Chicago, IL 60637

and NBER

Tel: (773) 834-2861

Email: amil.petrin@gsb.uchicago.edu

WWW: http://gsb.uchicago.edu/fac/amil.petrin 


\section{Introduction}

Every year consumers benefit from a greater breadth of choice in both the kind and quality of many products. Producers are the driving force behind these improvements as they seek the transitory market power associated with being the first-mover. This source of economic growth includes the improvements in existing goods and the production of entirely new goods, and can readily be observed in products like automobiles, consumer electronics, and health care. ${ }^{1}$

This paper measures the economic effects of the minivan introduction. In doing so, I develop a technique useful for obtaining more precise estimates of demand and supply curves when using market-level data on prices, quantities sold, and characteristics. Using this technique, I am able to quantify welfare benefits accruing to both consumers and non-consumers of minivans. I provide measures of the extent of first-mover advantage and profit cannibalization both initially by the innovator and later by the imitators. Additionally, I show that standard approaches yield results that are economically and statistically different from those obtained with my extension.

Discrete choice models were introduced by Gorman-Lancaster and developed econometrically in McFadden (1981). Much of the recent focus has been on addressing the endogeneity of price and on capturing important aspects of consumer heterogeneity, given the usual data, modeling, and computational constraints. Results from Berry, Levinsohn, and Pakes (1995) (heretofore BLP) show the importance of allowing for heterogeneity in consumer tastes when estimating cross-price elasticities. However, they have difficulty obtaining precise estimates of the variation in tastes, which requires a number of observations on how consumers substitute as available price and product characteristics in the choice set vary. Since BLP, many studies have reported the same result, primarily because we usually observe just a few market outcomes and/or these outcomes often do

\footnotetext{
${ }^{1}$ Welfare consequences of new product introductions have recently received increased attention from economists (in particular, see Bresnahan and Gordon (1997).) Papers focusing on buyer benefits from new products cover a range of goods, including automobiles (Feenstra (1988), Berry, Levinsohn, and Pakes (1993), Fershtman and Gandal (1998)), computers (Bresnahan (1986), Greenstein (1994)), health care technology (Trajtenberg (1989)), breakfast cereals (Hausman (1997a)), telecommunications services (Hausman (1997b)), and cellular phones (Hausman (1998)). New products have also been the focus of economists' attempts at revising the Consumer Price Index, in part because of findings by Armknecht (1984) that changes in the index are mostly due to price inflation from new products.
} 
not contain sufficient variation in price and product characteristics.

Berry, Levinsohn, and Pakes (1998) show that much more precise estimates of substitution patterns obtain when consumer-level data on first and second choices is observed. Unfortunately, this data cannot generally be posed as the answer because it rarely exists, and, when it does, is usually proprietary.

In this paper I offer an alternative solution: augment market-level data with data that relates the average characteristics of consumers to the characteristics of the products they purchase. This kind of data is more readily available than consumer-level data, and my results show that even limited additional information can play a useful role in estimating elasticities and consumer welfare. One might find this kind of information in supplemental surveys associated with any of the detailed panels often used by social scientists. Other possible sources include marketing or customer satisfaction surveys, which frequently appear in news and industry periodicals. Finally, very complete micro data may exist, but it also may be inaccessible to researchers, either for confidentiality reasons (e.g. Census or IRS data) or because it is prohibitively expensive to obtain. In either case, averages of the micro data may circumvent these problems by either satisfying disclosure requirements or reducing the cost of access.

The paper is organized in the following manner. Section 2 provides a brief history of the economics surrounding the minivan history. Section 3 reviews welfare estimators in differentiated goods markets. Section 4 outlines the utility specification and Section 5 discusses the supply side. The different sources of data are covered in Section 6 and the estimation procedure is outlined in Section 7. Sections 8 and 9 report results and conclusions.

\section{The Minivan Innovation}

The introduction of the minivan and the ensuing response of competitors to its popularity sheds light on firms motivation to innovate, including the degree to which a first-mover advantage can be maintained. In this section I provide a history of the minivan as it relates to these economic issues; readers not interested in these details can skip to section 3 with no loss in continuity.

The idea for an all-purpose family compact van had been circulating the car industry 
since at least the 1950's, the heyday of the station wagon. ${ }^{2}$ Early minivan prototypes included the Volkswagen Microbus and Corvair Greenbriar, introduced in 1949 and 1960 respectively. Both of these garageable family vans had more interior space than the average vehicle, but they were rear-wheel drive, rear-engined vehicles with swing-axle (non-independent) suspensions. These features resulted in poor performance and handling, and a less than smooth ride for passengers. Plush-interiored full-size passenger vans with luxury sedan options emerged as popular vehicles with certain crowds during the late 1960s and 1970s. However, they were not garageable at many homes and their poor handling also made them unpopular with many drivers.

In the early 1970s, a Ford designer named Don DeLaRussa recognized this shortcoming of the new vehicle market. This led him to an idea he would call the "Mini/Max". His insight was to build a front-wheel drive functionally-sized box better suited for errands and hauling the family than the conventional station wagon. ${ }^{3}$ The front-wheel drive would provide car-like handling and a smooth ride. It would also allow the drivetrain, that is, the engine, transmission, and differential, to be packaged together at the front of the vehicle, increasing the potential size of the passenger compartment. The "Mini/Max" idea received support from only one of Ford's top managers, Harold Sperlich. Other managers were concerned that this family vehicle would cannibalize Ford's healthy station wagon sales, which had been strong throughout the 1970s. DeLaRussa's idea would sit dormant for a decade, an apparent victim of strong station wagon sales. ${ }^{4}$

Rebirth of the minivan idea occurred during the early 1980s at the troubled Chrysler Corporation of America. Lee Iacocca, the Chairman of Chrysler, was a former Ford manager who at the time was most famous for presiding over the team that designed the Mustang. ${ }^{5}$ He took over the ailing Chrysler in 1979 and brought with him from Ford a

\footnotetext{
${ }^{2}$ These family haulers commanded $15 \%$ of the automobile market in 1957, their highest share ever. Their predecessor, the "depot hack," was also a people hauler. "Depot hacks" would take travelers from the train depot on the outskirts of town to the downtown hotels. They were usually converted truck or touring car chassis which had seats placed one behind another to carry a maximum body count. As "train depots" gave way to "train stations", "depot hacks" became "station wagons."

${ }^{3}$ DeLaRussa came to the U.S. from Europe, where he worked as a car designer. In Europe, the better handling of front-wheel drive was popular with drivers who had to negotiate many narrow, winding roads.

${ }^{4} \mathrm{Much}$ of the discussion in this section comes from Yates (1996), and from a number of (mostly) industry publications, including various issues of Motor Trend, Popular Mechanics, Popular Science, Wards Automotive, Automotive News, Consumer Reports, Fortune, Newsweek, and Time.

${ }^{5}$ In 1961, as a young General Manager at Ford, he managed the redesign of the mundane Ford Falcon
} 
number of colleagues, including DeLaRussa and Sperlich. After convincing Congress to bail the company out, Iacocca quickly began rebuilding Chrysler's beleaguered product line. ${ }^{6}$ His plan was to spin most new models off of a single platform - drivetrain, floorpan, and suspension - to create a variety of vehicles. Using the front-wheel drive K-car platform of the Dodge Aries/Plymouth Reliant, Chrysler produced the Chrysler LeBaron/Dodge 400, the Chrysler E-Class/Dodge 600, and the luxury Chrysler New Yorker. Sperlich continued to push the minivan idea, and Iacocca agreed, allocating $\$ 700$ million towards its development.

Prior to their introduction, Chrysler executives believed the new minivans would replace station wagons. However, the numerous names dubbed them suggest that it was not clear which market niche, if any, would be filled by these vehicles. ${ }^{7}$ The new and innovative dimensions of the minivan, different from any other available vehicle at the time, gave rise to the alternative titles of compact van, garageable van, and super station wagon. The Plymouth Voyager/Dodge Caravan had an overall length of 176 inches, shorter than both the standard Dodge B-150 full-size van and the luxury LeBaron station wagon by four and three inches respectively. At just over 6 feet wide, it was just an inch wider than the station wagon and almost a foot slimmer than the B-150 full-size van. With a height of 64 inches, the minivan lay between the 53 inch LeBaron and the 80 inch B-150 van. This in-between size, with the "height-induced roominess" instead of roominess from the length, loosens the vehicle space-constraint considerably. Additional interior space and easier entry via a low step-in came from lowering the floorpan (the bottom of the vehicle), which could be dropped with front-wheel drive because the drivetrain no longer had to run underneath the length of the vehicle (to the rear-drive wheels.) Lowering the floorpan also had an added benefit; passengers could move from the front to the back of the vehicle

into the successful Mustang. By adapting the Falcon's engine, transmission, and axles, Iacocca slashed the cost of development to one-fourth that of a standard new car. In the end, he produced a sporty Ford Mustang that ended its first year with a new annual sales record of 418,000. Later successes with the Mercury Cougar and Marquis and the higher end Lincoln Mark III established Iacocca as a significant figure in the automotive industry (see Iacocca (1986).)

${ }^{6}$ Despite strong opposition from much of the business community, Iacocca obtained passage of the Loan Guarantee Act at the end of 1979. This bail-out was the largest financial transaction in U.S. history, and included loan guarantees of up to $\$ 1.5$ billion. Participants included 452 banks, three foreign countries, four states, 1500 dealerships and suppliers, and the UAW and five other unions.

${ }^{7}$ Motor Trend's June, 1987 issue reported "... as consumers, we are still trying to figure out specifically what they (minivans) are. Genetic analysis reveals they are part bus, part stevedore, and part limousine." 
without exiting it.

The move to front wheel drive was a second major innovation. It provided improved handling over the rear-wheel drive vehicles of the day for a few reasons. First, the power from the engine goes directly to the front wheels, over which the driver has control. Second, the weight of the engine sits over the drive wheels. Finally, it led Chrysler to improve the suspension.

The new suspension concept of the minivan was specifically designed to accomodate the largest front-wheel drive vehicle in the new car market. Instead of leaf springs, the minivan was equipped with an independent front suspension based on a modified form of the McPherson strut, a technology common to passenger cars of the day. Leaf springs, literally a horse-and-buggy technology, were inexpensive and well-designed to handle large loads. At the time, they exclusively equipped both the front and rear wheels of all trucks and vans. The disadvantage of this technology lay in its inability to stop the transmission of the normal bumps and bruises to the frame of the body, where it is then passed on to the passengers. McPherson struts have coil springs, which are much better suited to absorbing bumps. The struts are also designed to counter other physical forces acting on moving vehicles that can destroy the ride and handling. ${ }^{8}$

On October 7, 1983, the first Dodge Caravans and Plymouth Voyagers began rolling off the assembly line. This new vehicle was an immediate success; Chrysler sold almost 170,000 Caravans in 1984, its debut year, capturing $1.58 \%$ of the new vehicle market. General Motors (GM) and Ford quickly responded, introducing their own versions of minivans in 1985 (GM Astro/Safari) and 1986 (Ford Aerostar.) However, because they did not forecast the minivan's success, they had little choice but to build their minivans on truck platforms with rear-wheel-drive, and their versions handled more like down-sized full-size vans than passenger cars. It was not until six years later, the average time from drawing board to showroom, that GM delivered the first minivan competitor with front wheel drive to market.

Five years after its introduction, Americans had bought over 2.25 million minivans, with Chrysler selling 1.3 million of these new vehicles to households who willingly paid (at least) the base sticker price of $\$ 8700$ (1982-84 CPI adjusted.) This and later success obtained from Chrysler's continual effort to monitor the likes and dislikes of its customers,

\footnotetext{
${ }^{8}$ For example, the independence of one front wheel's suspension from the other also minimizes transmission of shocks across the axle (and eventually into the passenger compartment).
} 
using its first-mover informational advantage to guide the later innovations on its minivans. ${ }^{9}$ In 1997, fourteen years after the minivan introduction, with six firms marketing a total of thirteen different kinds of minivans, Chrysler still dominated this market niche, claiming $44 \%$ of the total 1.16 million units sold that year.

Ford and GM, the dominant station wagon sellers, watched as the wagon sales peaked in 1984 at 950,000 and then plummeted over the next seven years to 300,000. Industry analysts echoed Ford managers' fears of the "Mini/Max", concluding that the minivan had replaced the station wagon.

\section{Discrete Choice Demand and Welfare Estimation}

In this section I review the Gorman-Lancaster-McFadden discrete choice model with a focus on recent progress in demand and welfare estimation using market-level data. I then describe my suggestion for obtaining more precise estimates of the distribution of unobserved heterogeneity in consumer tastes.

\subsection{Overview and Recent Developments}

Discrete choice models start with conditional indirect utility, usually given as a function of observed and unobserved product $j$ and consumer $i$ characteristics and model parameters $\theta$. Given these arguments, it is straightforward to solve for the conditional indirect utility for any product $j, u_{i j}(\theta)$, and for the level of unconditional indirect utility that obtains for any choice set $\mathrm{J}$, or

$$
V_{i}^{J}(\theta)=\max _{j \in J} u_{i j}(\theta)
$$

These models lend themselves naturally to true cost-of-living indices, which fix a benchmark level of utility and ask how income must change to reach this utility level (see Hicks (1946).) With new products, one reasonable benchmark utility level is that

\footnotetext{
${ }^{9}$ Two of the most striking examples relate to the engine and the two sliding doors. The early Dodge Caravan came with a 4-cylinder (low horsepower) engine, but consumer complaints led Chrysler to replace this engine in 1987 with a higher performance 6-cylinder engine. Chrysler was also the first to put two sliding doors on a minivan, a very popular feature that was quickly imitated by General Motors and Ford. Parents appreciated the two sliding doors because kids could now exit from either side of the street onto the sidewalk or from either side of the vehicle in the garage.
} 
obtained when consumers have the new good in their choice set, or, $V_{i}^{B}=V_{i}\left(p^{0}, y_{i}\right)$, where choice set B includes the new good, $y_{i}$ is income and $p^{0}$ is the vector of prices with the new good available. Compensating variation uses this benchmark utility and asks how much consumers need to be compensated to willingly give up the new good; that is, it is the change in income $\Delta y$ that solves

$$
V_{i}^{B}=V_{i}\left(p^{0}, y_{i}\right)=V_{i}\left(p^{1}, y_{i}+\Delta y\right)
$$

where $p^{1}$ is the equilibrium price vector with the new good price set high enough such that demand is zero (e.g. infinity.) Thus, it will depend on a consumer's income and the prices that obtain in the market both with and without the new good.

A general random utility model is given by the following three-component function:

$$
u_{i j}(\theta)=\delta_{j}(\theta)+\mu_{i j}(\theta)+\epsilon_{i j}
$$

The first component, $\delta_{j}(\theta)$, is a product specific utility term common to all consumers. The $\mu_{i j}(\theta)$ term represents heterogeneity in consumer tastes for observed product characteristics. Finally, $\epsilon_{i j}$ is a "love of variety" taste term that is assumed to be i.i.d. across products and consumers. Consumer $i$ is assumed to choose the product $j$ that yields maximal utility, and market shares obtain from aggregating over consumers.

The utility component common to all consumers, $\delta_{j}$, can be written as

$$
\delta_{j}=-\alpha p_{j}+X_{j} \beta+\xi_{j}
$$

where $\alpha$ is the marginal utility of income, $X_{j}$ and $\beta$ are, respectively, a vector of observed product characteristics and the taste parameters associated with those characteristics. $\xi_{j}$ represents utility derived from characteristics observed to consumers and producers but not observed to the econometrician.

The $\mu_{i j}$ term allows substitution patterns to reflect heterogeneity in consumer tastes for product characteristics. This heterogeneity may be driven by differences in demographics and/or idiosyncratic tastes. BLP show that allowing for these tastes is important for getting realistic substitution patterns and cross-price elasticities; without them, the only consumer taste heterogeneity arises from $\left(\epsilon_{i j}\right)$, which is i.i.d. across consumers and products. ${ }^{10}$ Thus, without $\mu_{i j}(\theta)$, all consumers share the same expected ordering over the

\footnotetext{
${ }^{10}$ See also Nevo (1998).
} 
products (that given by the $\delta_{j}$ 's.) In terms of substitution patterns, this ordering means that any consumer that loses her first choice is always more likely to substitute to the vehicles with the largest $\delta_{j}$ 's, regardless of the characteristics of her first choice.

One of the negative results that obtains from recent demand estimation is that parameters describing the distribution of $\mu_{i j}(\theta)$ are often difficult to precisely estimate with market-level data. This result obtains because precise identification of substitution patterns requires observations on how consumers substitute between products as the set of available choices changes. ${ }^{11}$ With market-level data, we often do not observe many market outcomes and/or the various market outcomes sometimes do not contain a lot of variation in price and product characteristics. Berry, Levinsohn, and Pakes (1998) show that precise estimates of substitution patterns do obtain when one observes consumer-level first and second choices; thus, "micro-micro" data can identify the distribution of $\mu_{i j}(\theta)$. Unfortunately, this data cannot be posed as the solution because it rarely exists, and, when it does, is usually proprietary. Before turning to my suggestion for obtaining more precise estimates of $\mu_{i j}(\theta)$, I briefly describe the importance of the product-specific errors.

Until recently, discrete choice models with market-level data often ignored the $\xi_{j}$ 's, in essence assuming that the (usually half dozen or so) observed characteristics provide a complete description of what consumers value. As Berry, Levinsohn, and Pakes (1995) note, without this term, the only source of variance in the model is sampling error. With market-level data this variance is often too small to account for discrepancies between predicted and observed market shares, and in such cases formal testing rejects the model specification in favor of the "overfitting" alternative.

Introducing these product-specific errors makes an otherwise dormant endogeneity is-

\footnotetext{
${ }^{11}$ Figure 1 provides a suggestion of how identification obtains from observing variation in choice sets. Consider a market with three cars that differ only in the amount of their interior space; two cars have lots relative to the third (choice set 1.) In this first market, we see each car obtaining equal market shares of one-third. In a second market (say in the following year or in a different geographic region), one of the vehicles with lots of interior space is no longer available. I describe two extreme outcomes for market shares and their information content. In the first case, the remaining vehicle with large interior space obtains two-thirds of the market; thus consumers appear to substitute entirely to the vehicle with lots of interior space, suggesting these consumers have strong taste for interior space. Furthermore, they disagree with the consumers purchasing the car with limited interior space, so there is evidence of heterogeneity in tastes for interior space. In the second extreme case, the two remaining vehicles split the market share. This change provides no evidence of heterogeneity in taste for interior space as consumers appear to randomly sort between the two available alternatives.
} 
sue apparent; if there are unobserved (to the econometrician) characteristics, and these characteristics are observed to both consumers and producers, price is likely to be positively correlated with these errors. This correlation biases the marginal utility of income term towards zero, as consumers appear less price sensitive than they actually are (see, e.g. Trajtenberg (1989).) Instrumental variable (IV) methods are the usual solution, although their application is frustrated by the fact that both the $p_{j}$ and $\xi_{j}$ enter the share equations in a non-linear fashion. Berry (1994) provides an important advance, developing a method that makes IV applicable to a large class of non-linear random utility models. I now turn to my suggestion.

\subsection{Identifying Heterogeneity Using Secondary Data Sources}

I offer a middle-of-the-road approach to obtaining more precise estimates of the parameters in $\mu_{i j}(\theta)$. I suggest using data from a secondary source on some relevant average characteristics of consumers associated with some of the relevant attributes of the products they purchase. In particular, for my welfare question I incorporate information from a supplement to the Consumer Expenditure Survey (CEX) on new vehicle purchasers. I use this information to help identify the marginal utility of income and substitution patterns between vehicles in the family vehicle segment. For the marginal utility of income, I allow for income effects (indexing $\alpha$ by $i$,), matching the model predictions for probability of purchase across income groups to the observed conditional purchase probabilities from the CEX. I also match model predictions for average household characteristics (like family size) for purchasers of different vehicles to those in the CEX data.

This approach has a number of appealing features. First, this kind of information is more likely to be available to researchers. One might find this kind of information on average characteristics in supplemental surveys associated with any of the detailed panels often used by social scientists. Other possible sources include marketing or customer satisfaction surveys. Second, while micro data is always preferred, averages of micro data may be more readily available because they satisfy the disclosure requirements of confidential data or are less expensive to purchase than the full collection of data. Third, the approach adds no real computational burden to BLP. Once one has the additional averages that one wants the model to match, augmenting the market-level data is done by adding the new moments to the BLP estimation routine. And since the sampling 
variation in the supplemental data is typically independent of the sampling variation in the market-level data, the variance of the combined moments is block diagonal, making computation of the objective function and the standard errors less burdensome.

Finally, my results suggest that even limited additional information can play an important role in more precisely estimating the parameters associated with the distribution of unobserved heterogeneity. In particular, the role of the independent and identically distributed (i.i.d. ) error terms is reduced, and I find this leads to much more reasonable estimates of the marginal utility of income, own-and cross-price elasticities, and welfare change. I now turn to the specifics of the utility function.

\section{The Utility Specification}

In this section I describe the utility specification, which is tailored to allow for individual tastes that can vary across consumers both because of their demographics and because they may have strong idiosyncratic taste for observed vehicle characteristics.

The utility function has consumer $i$ choosing the good $j$ that maximizes

$$
u_{i j}=\alpha_{i} \ln \left(y_{i}-p_{j}\right)+X_{j} \beta+\sum_{k} \gamma_{k} \nu_{i k} x_{j k}+\xi_{j}+\epsilon_{i j}
$$

where $X_{j}, \beta, \xi_{j}$, and $\epsilon_{i j}$ are as described in Section 3 and $x_{j k} \in X_{j}$. Utility from the composite commodity good is given by $\alpha_{i} \ln \left(y_{i}-p_{j}\right)$. Income effects are prevalent in the survey data, so I allow the marginal utility of income to vary according to income groups:

$$
\alpha_{i}= \begin{cases}\alpha_{0} & \text { if }\left(y_{i} \leq \bar{y}_{1}\right) \\ \alpha_{1} & \text { if }\left(\bar{y}_{1} \leq y_{i}<\bar{y}_{2}\right) \\ \alpha_{2} & \text { if }\left(y_{i} \geq \bar{y}_{2}\right)\end{cases}
$$

where $\bar{y}_{1}$ and $\bar{y}_{2}$ divide the U.S. population into three equally sized groups ordered by income. The $k$ th characteristic of vehicle $j$ is given by $x_{j k}$, for $k=1, \ldots, K$. Each consumer $i$ has $K$ idiosyncratic tastes for the $K$ observed characteristics, $\nu_{i}=\left(\nu_{i 1}, \ldots, \nu_{i K}\right)$. The consumer specific $\nu_{i k}$ are interacted with $\gamma_{k}$, a parameter measuring the heterogeneity in tastes for the observed characteristics in the population. This yields $\gamma_{i k}$, consumer $i$ 's personal taste for characteristic $k$,

$$
\gamma_{i k}=\gamma_{k} \nu_{i k}
$$


I allow the $\gamma_{i k}$ 's associated with minivans, station wagons, full-size passenger vans, and sport-utility vehicles to depend in a special way on demographics. Specifically, if $f s_{i}$ is the family size of household $i$, and, for example, $m i$ and $s w$ subscripts denote minivan and station wagon, consumer $i$ 's tastes are

$$
\begin{aligned}
\gamma_{i, m i} & =\gamma_{m i} \ln \left(f s_{i}\right) \nu_{i f} \\
\gamma_{i, s w} & =\gamma_{s w} \ln \left(f s_{i}\right) \nu_{i f}
\end{aligned}
$$

where $\nu_{i f}$ is a common idiosyncratic taste $i$ has for family vehicles (independent of demographics) and $\left(\ln \left(f s_{i}\right) \nu_{i f}\right)$ is the full demographic-dependent taste term. The parameter $\gamma_{m i}\left(\gamma_{s w}\right)$ is a taste-shifter that allows families of different sizes to value minivans (station wagons) differently. With this parameterization, the covariance between taste for minivans and taste for station wagons is increasing in $\gamma_{m i}$ and $\gamma_{s w}$. Thus, patterns of substitution between family vehicles can emerge for 2 reasons: larger families prefer these vehicles, and/or the vehicles share other similar observed characteristics.

After integrating over the logit "love of variety" error the probability household $i$ purchases good $j$ is given by:

$$
\operatorname{Pr}(j \mid X, i)=\frac{e^{\alpha_{i} \ln \left(y_{i}-p_{j}\right)+X_{j} \beta+\sum_{k} \gamma_{k} \nu_{i k} x_{j k}+\xi_{j}}}{\sum_{l} e^{\alpha_{i} \ln \left(y_{i}-p_{l}\right)+X_{l} \beta+\sum_{k} \gamma_{k} \nu_{i k} x_{l k}+\xi_{l}}} .
$$

Aggregate demands $s_{j}$ obtain from integration over household-specific characteristics, so

$$
s_{j}=\int_{i} \operatorname{Pr}(j \mid X, i) P(d i)=\int_{i} \frac{e^{\delta_{j}+\mu_{i j}}}{\sum_{l} e^{\delta_{l}+\mu_{i l}}} P(d i),
$$

where $i$ indexes income, family size, and the vector of unobserved tastes $\left(y_{i}, f s_{i}, \nu_{i}\right)$. The joint distribution of income and family size from the CEX is used to integrate out $\left(y_{i}, f s_{i}\right)$. I use $\mathrm{K}$ independent $\chi^{2}(3)$ distributions truncated at $95 \%$ to approximate the distribution of unobserved consumer tastes. While perhaps ad hoc (as this choice always is), I choose this distribution for two reasons. First, it is bounded above and below. Second, using $\chi^{2}$ instead of the normal distribution implies that taste heterogeneity in the population is skewed toward the direction of strong positive taste. Having specified the distribution of consumer characteristics, the demand side is complete. 


\section{The Supply Side}

In this section I discuss the supply side model. It is identical to the approach used by BLP, and I use it two reasons. First, given the observed market shares, prices and characteristics, and the demand side model, one can invert the equilibrium first order conditions to solve for product-specific marginal costs. Since information on marginal costs is proprietary and very difficult to obtain, this approach permits me to estimate these costs, which I use to measure changes in producer surplus. Second, it's computationally possible to solve for new equilibrium price vectors under different counterfactuals. Solving for new equilibrium price vectors is important because I want to account for the price effects of imperfect competition when computing consumer and producer changes in welfare.

The competitive environment has $F$ multiproduct firms competing on price. Each firm $f$ produces some subset $J_{f}$ of the $J$ total products. Firms have a marginal cost function that is log-linear in a vector of $k^{\prime}$ cost characteristics. Similar to the demand side, the cost characteristics are separated into an observed and an unobserved component. The vector $W_{j}$ represents the observed component, and $\omega_{j}$ the unobserved component. Given these assumptions, the (log) marginal cost function can be written

$$
\ln \left(m c_{j}\right)=W_{j} \tau+\omega_{j}
$$

where $\tau$ is a vector of cost parameters associated with product characteristics.

Each firm has a profit function

$$
\Pi_{f}=M \sum_{j \in J_{f}}\left(p_{j}-m c_{j}\right) s_{j}(p, X ; \theta)
$$

where $\mathrm{M}$ is the number of households in the U.S., $s_{j}(\cdot)$ is good $j$ 's predicted market share, and $q_{j}(p, X ; \theta)=M s_{j}(p, X ; \theta){ }^{12}$ Firms are assumed to compete in a Bertrand-Nash fashion; given their products and the prices and attributes of competing products, firms choose prices to maximize profits.

In this model, any product sold by the optimizing firm $\mathrm{f}$ will have a price and market

\footnotetext{
${ }^{12}$ This profit function ignores the $25 \%$ tariff levied against Japanese minivans during the 1980 s. While it is possible to incorporate this tariff into the model, I do not complicate matters simply because Japanese minivans make up a trivial part of minivan sales.
} 
share satisfying the first order condition

$$
s_{j}(p, X ; \theta)+\sum_{r \in J_{f}}\left(p_{r}-m c_{r}\right) \frac{\partial s_{r}(p, X ; \theta)}{\partial p_{j}}=0 .
$$

With $p$ and $s$ observed, if $\frac{\partial s_{r}(p, X ; \theta)}{\partial p_{j}}$ (which comes from the demand side model) is overestimated, (5.2) makes it clear that markups of the firm will be underestimated, thus contaminating measure of producer profits.

Defining a new JxJ matrix, $\Delta$, whose (j,r) element is

$$
\Delta_{j r}=\left\{\begin{array}{ll}
-\frac{\partial s_{r}}{\partial p_{j}} & \text { if } \mathrm{j} \text { and } \mathrm{r} \text { are produced by the same firm } \\
0 & \text { otherwise }
\end{array}\right\},
$$

the J first order conditions from (5.2) can be written as

$$
s\left(p_{0}, X ; \theta\right)-\Delta\left(p_{0}, X ; \theta\right)\left[p_{0}-m c\right]=0,
$$

where $p_{0}$ is the (observed) equilibrium price vector. This system of equations can be inverted to solve for the price-cost markups:

$$
p_{0}-m c=\Delta\left(p_{0}, X ; \theta\right)^{-1} s\left(p_{0}, X ; \theta\right) .
$$

Since prices are observed and markups can be explicitly evaluated using $\Delta\left(p_{0}, X ; \theta\right)^{-1} s\left(p_{0}, X ; \theta\right)$, estimates of marginal costs $(m c)$ can be computed. Using (5.3) and (5.1), the estimating equation is

$$
\ln (m c)=\ln \left(p_{0}-\Delta\left(p_{0}, X ; \theta\right)^{-1} s\left(p_{0}, X ; \theta\right)\right)=W \tau+\omega,
$$

where $W$ is a $J \times k^{\prime}$ matrix of new vehicles by observed cost side characteristics.

In order to compute the change in both consumer and producer profits, I use (5.2) to solve for a new equilibrium price vector for different counterfactuals. The new equilibrium price vector $p_{1}$ that obtains with the new choice set is used to compute the change in variable profits, $\Delta \Pi_{f}\left(p_{0}, p_{1}, m c ; \theta\right)$ for each firm $f$, and $\sum_{f} \Delta \Pi_{f}$ gives the total change in producer profits.

\section{Data}

I draw from a number of different data sources for this work. The data set includes all 2407 nameplates marketed in the U.S. from the years 1981 to 1993 with sales over 1000 vehicles, 
including three years, 1981-1983, for which minivans were not available to consumers. The product level information combines data recorded in the Automotive News Market Data Book and in Wards Automotive Yearbook, with most information on passenger cars coming from the former, while the latter provided detailed information on station wagons, minivans, sport-utility vehicles, and full-size passenger vans. ${ }^{13}$ Vehicle characteristics include a measure of acceleration (horsepower/curb weight), vehicle dimensions, drive type, fuel efficiency, and a measure of luxury (a/c standard.) Quantity sold and list price are then linked to the characteristics of the base model. Econometrically, nameplate/year observations that lie in adjacent years and do not change horsepower, wheelbase, width or length by more than 10 percent are treated as the same model. Given this definition, there are 916 distinct models.

The Consumer Expenditure Survey (CEX) is a rotating panel recording a U.S. households purchasing pattern behavior for 5 quarters. I use the years 1987-1992, which includes a total of close to 30,000 households. It contains an automobile supplement which has information on the demographics of new vehicle purchasers and of family vehicle purchasers. Unfortunately, only 400 new vehicle purchases are reported annually, while there are about 200 different kinds of vehicles marketed annually, frustrating efforts to use the micro data directly. ${ }^{14}$ It does, however, contain questions which allow me to identify a subset of purchasers for my primary vehicles of interest, i.e. minivans, station wagons, sport-utility vehicles, and full-size vans. I use family size and head-of-household age to compute averages for purchasers of these types of vehicles. In the case of minivans, station wagons, sport-utilities, and full-size vans, the sample size is limited, with these vehicle types having 120,63, 131, and 23 observations each. In total I observe 2660 new vehicle purchases over this 6 year period, and I use this information to compute estimates of purchase probabilities given consumer income levels. Finally, I use the full 30,000 observations to approximate the empirical joint distribution of family size and income in the United States.

Annual observations on a number of microeconomic and macroeconomic variables are also included. The number of households $(M)$ in the U.S. comes from the Statistical Abstract of the U.S., as do prices for a gallon of unleaded gas in the 1990s. Gasoline

\footnotetext{
${ }^{13} \mathrm{My}$ thanks to BLP for providing me with the data on passenger cars and to Rob Feenstra for data on prices and quantities sold for many of the early 1980s full-size vans and sport utilities.

${ }^{14}$ See Goldberg (1995) for a more complete discussion of this data.
} 
prices in the 1980s are taken from the U.S Department of Commerce's Business Statistics. Figures on GNP are drawn from the Economic Report of the President. Finally, the lognormal parameters of the distribution of income in the U.S. were estimated using data from the annual March Current Population Surveys (used for the random coefficients approach with just aggregate data.)

\section{Estimation}

In this section I describe my estimation strategy. It closely resembles the Generalized Method of Moments (GMM) approach taken by BLP, except that I supplement their moments with a new set of moments.

\subsection{The New Moments}

The idea for using these new moments relates to a suggestion by Imbens and Lancaster (1994). They point out that aggregate data is aggregated micro data, and therefore contains information on the average of micro variables. In my case, the CEX automobile supplement provides information on aggregates of new car purchasers. The GMM estimation routine essentially chooses the parameter estimates to match (in part) the average model predictions to the observed average CEX outcomes.

The first set of new moments matches average probability of new vehicle purchase conditional on income level, thus providing more precise identification of the income effect parameters $\left(\alpha_{1}, \alpha_{2}, \alpha_{3}\right)$. These moments are given by

$$
\begin{aligned}
& E\left[\{i \text { purchases new vehicle }\} \mid\left\{y_{i}<\bar{y}_{1}\right\}\right] \\
& E\left[\{i \text { purchases new vehicle }\} \mid\left\{\bar{y}_{1} \leq y_{i}<\bar{y}_{2}\right\}\right], \text { and } \\
& E\left[\{i \text { purchases new vehicle }\} \mid\left\{y_{i} \geq \bar{y}_{2}\right\}\right]
\end{aligned}
$$

where $\{i$ purchases new vehicle $\}$ is the event that consumer $i$ purchases a new vehicle, and $\left\{y_{i}<\bar{y}_{1}\right\},\left\{\bar{y}_{1} \leq y_{i}<\bar{y}_{2}\right\}$, and $\left\{y_{i} \geq \bar{y}_{2}\right\}$ are, respectively, the events that consumer $i$ is in the low, middle, and high income group. I also match the model predicted averages 
to those observed in the CEX for the moments

$$
\begin{aligned}
& E\left[f s_{i} \mid\{i \text { purchases a minivan }\}\right], \\
& E\left[f s_{i} \mid\{i \text { purchases a station wagon }\}\right], \\
& E\left[f s_{i} \mid\{i \text { purchases a sport utility }\}\right], \text { and } \\
& E\left[f s_{i} \mid\{i \text { purchases a full-size van }\}\right],
\end{aligned}
$$

which respectively are the average family size of purchasers of minivans, station wagons, sport utilities, and full-size vans. Finally, I include four moments that match the probability head-of-household is between age 30 and 60 for each of these four family vehicle groups.

\subsection{The BLP Moments}

One might describe the BLP approach as using two different sets of moments. The first set of moments matches the model's share predictions $\left(s_{j}(\delta(\theta), \theta)\right)$ to those in the data $\left(\mathbf{s}_{j}\right)$, or

$$
s_{j}(\delta(\theta), \theta)-\mathbf{s}_{j}=0, \quad j=0,1, \cdots, J .
$$

This moment matching is equivalent to solving for the vector $\delta(\theta)$ of product dummy variables that matches the predicted to the observed market shares, which Berry (1994) shows exists and is unique under mild regularity conditions on the distribution of consumer tastes. $^{15}$ These moments cannot identify additional parameters as there are $J$ moments that exactly identify the $J$ elements of $\delta$ (one element is normalized to zero.)

The second set relates to the market-level disturbances $\left(\xi_{j}(\theta), \omega_{j}(\theta)\right)$. Except for price, the unobserved demand and supply disturbances for any vehicle $j$ are assumed to be uncorrelated with observed demand and cost side variables of all vehicles in that year, or

$$
E\left[\xi_{j}\left(\theta_{0}\right) \mid(X, W)\right]=E\left[\omega_{j}\left(\theta_{0}\right) \mid(X, W)\right]=0 .
$$

While admittedly a strong assumption, it does not impose the frequently used stronger assumption that own-product price is uncorrelated with the own-product error. Instead, it assumes that just the product characteristics are exogenous.

\footnotetext{
${ }^{15}$ While Berry's discussion and examples are all couched in terms of mean utility, his proof of existence and uniqueness carries directly over to my utility framework, where $\delta$ acts as a vector of base utilities for each product.
} 
I follow BLP's approximation to the optimal instruments. Product l's characteristics are valid instruments for themselves. For prices, two sets of instruments are available. The first set are cost side variables that are excluded from the demand equation. The second set derive from the equilibrium first order conditions from (5.2), where firm $f$ 's choice of its product l's price is determined by its proximity in characteristics space to competing products and to its own-firm products. In any year, a first order approximation to the optimal instruments is given by the sum of the characteristic $k$ across other own-firm products, or $\sum_{j \neq l, j \in J_{f}} x_{j k}$, and the sum of the characteristic across competing firms, or $\sum_{j \notin J_{f}} x_{j k} \cdot{ }^{16}$ This completes the description of the moments.

\subsection{The Objective Function}

The two sets of moments that enter the GMM objective function are $G_{1}(\theta)$, the BLPlike moments, and $G_{2}(\theta)$, the moments associated with the CEX data. The population moment conditions are assumed to uniquely equal zero at the truth $\theta_{0}$, or

$$
E\left[G\left(\theta_{0}\right)\right]=E\left[\begin{array}{l}
G_{1}\left(\theta_{0}\right) \\
G_{2}\left(\theta_{0}\right)
\end{array}\right]=0 .
$$

Hansen (1982) shows that the optimal (two-step) GMM estimator takes the form

$$
\widehat{\theta}=\arg \min _{\theta \in \Theta} G^{*}(\theta)^{\prime} G^{*}(\theta),
$$

where $G^{*}(\theta)=a(\tilde{\theta}) \hat{G}(\theta), \hat{G}(\cdot)$ is the sample analog to $G(\cdot)$, and $a(\tilde{\theta})$ is a consistent estimate of the "square root" of the inverse of the asymptotic variance-covariance matrix of the moments (obtained using $\tilde{\theta}$, a preliminary consistent estimate of $\theta_{0}$.)

The two sources of variance in $V=E\left[G^{*}\left(\theta_{0}\right) G^{*}\left(\theta_{0}\right)^{\prime}\right]$ come from two independent sampling processes, so $V$ is block diagonal. The upper left hand block $V_{1}\left(G_{1}^{*}\left(\theta_{0}\right)\right)$ is the variance of the BLP-like moments, and the lower right hand block $V_{2}\left(G_{2}^{*}\left(\theta_{0}\right)\right)$ is the variance of the new moments. Letting $\Gamma=E\left[\frac{\partial G^{*}\left(\theta_{0}\right)}{\partial \theta}\right]$, the gradient of the moments with respect to the parameters evaluated at the true parameter values, the asymptotic variance of $\sqrt{n}\left(\hat{\theta}-\theta_{0}\right)$ is given by

$$
\left(\Gamma^{\prime} \Gamma\right)^{-1} \Gamma^{\prime} V \Gamma\left(\Gamma^{\prime} \Gamma\right)^{-1}
$$

\footnotetext{
${ }^{16}$ Bresnahan, Stern, and Trajtenberg (1997) provide a nice discussion of the intuition behind using these instruments.
} 
As usual, reported standard errors estimate $\Gamma$ and $V$ using the consistent estimates $\Gamma(\widehat{\theta})$ and $V(\widehat{\theta}) \cdot{ }^{17}$ I now turn to the results.

\section{Results}

I organize the results into six different sets of tables: descriptive statistics, parameter estimates, consumer welfare, markups and producer welfare, total welfare, and robustness results.

\subsection{Descriptive Statistics}

The descriptive statistics contain the essence of the story that the model structure and the later tables quantify. The average characteristics of new vehicles sold in the United States are reported in Table 1a, including averages for the different family vehicles (minivans, station wagons, sport utility vehicles, and full-size vans.) Except for the small, inexpensive station wagons, priced on average more that $\$ 3000$ (1982-84 CPI adjusted) less than other family vehicles, I find that family vehicles stand out from other vehicles primarily in their size and are priced competitively with one another. Most minivans and station wagons come equipped with front wheel drive (FWD), with Chrysler almost exclusively accounting for the $63 \%$ of FWD minivan sales. Finally, minivans also have the distinction of coming with more luxury; $78 \%$ have air conditioning (and presumably other features) as part of the list price package.

Table 1b summarizes income, family size, and head-of-household age for different new vehicle purchasers and for the United States population as a whole. Income effects for new automobiles exist; new vehicle purchasers have an average income almost $\$ 13,000$ higher than the average income of U.S. households, and this effect is even more pronounced for most of the family vehicles. Minivans, station wagons, sport-utilities, and full-size vans are typically purchased by larger families, and by households whose head is between the age of 30 and 60 . With an average family size of 3.86 and a probability of 0.78 that the head of household is between age 30 and 60 , minivans stand out most prominently as the

\footnotetext{
${ }^{17}$ Moment restrictions for models that are similar in nameplate and characteristics over time are aggregated into one sample observation. Thus, the standard errors of the parameter estimates permit product-specific errors for similar models to exhibit arbitrary correlation across years.
} 
family vehicle.

Table 1c presents summary sales figures for the family-vehicle market segment from 1981-93. Minivans sales climb dramatically in popularity over the 1980s, moving from a market share of $1.5 \%$ in 1984 to almost $10 \%$ in 1993 . The waning appeal of station wagons is closely correlated with the success of minivans; they control approximately $10 \%$ of the new car market in each year 1981, 1982, and 1983, but in 1984 (with the introduction of the minivan) their sales start to plummet, and fall every year until 1991. Further evidence in the market-level data of a covariance in taste between station wagons and minivans lies in column 5, which provides the sum of station wagon and minivan sales; while station wagon sales fell and minivan sales climbed, the sum of percentage sales remained remarkably constant over the sample period.

\subsection{Parameter Estimates}

Table 2 a reports the results for the four different demand-side models: OLS, IV, random coefficients with IV correction, and random coefficients with IV correction and the CEX data. OLS and IV results (columns 3 and 4) illustrate both the need to instrument and the need for permitting heterogeneity in taste. Even though the coefficient on price doubles with instruments (similar to BLP's finding) the estimated IV demand curves remain very inelastic, suggesting a specification problem. Both models are nested in the more general models reported in columns 1 and 2 that allow for unobserved heterogeneity in tastes, and Wald tests easily reject the OLS and IV models.

Column 2 reports the random coefficient demand estimates with just market-level data. They suffer from the usual problem of being imprecisely estimated; only 6 of 24 demand side parameter estimates have t-statistics that are greater than 1 , and not one of the eight coefficients that relate to the family vehicles has a t-statistic that is greater than 1. Thus, the 13 years of market-level data do not provide enough variation to precisely estimate the covariances in taste that are crucial to my welfare questions.

I extend the random coefficients approach so that family size can potentially influence preference for family vehicles, and I add the supplemental CEX information that relates tastes to consumer observables. I find that even the limited information provided by the CEX survey from Table 1b can significantly reduce the imprecision in a random coefficients model; 21 of the 24 parameter estimates with this new information have t-statistics greater 
than 1 . The parameters most closely related to the additional information show the biggest increase in precision. In particular, the coefficients related to family vehicles and income effects are much improved as all 11 coefficients have t-statistics greater than $3{ }^{18}$

The cost side parameters of the model are presented in Table $2 \mathrm{~b}$. All of the car characteristics enter with significant coefficients that are of the expected sign. It costs more to build more acceleration, bigger vehicles (measured by weight), better fuel efficiency, and more luxury into a new vehicle. Overall, the estimated precision of the demand and supply side parameters and the model predictions for the CEX moments are encouraging. I now turn to their implications.

\subsection{Changes in Consumer Welfare: 1984}

Here I compare the estimated changes in consumer welfare in 1984 across the four demand side models.

Table 3a summarizes the predicted changes in equilibrium prices that occur with the 1984 minivan entry into the new vehicle market. These price changes illustrate how increased price competition in an imperfectly competitive market can bring significant benefits to non-purchasers of the new product. The model suggests that the Dodge Caravan had many substitutes that were top-selling vehicles. In particular, station wagons (SW) experienced the largest percentage price decreases, and the large family sedans (LS) show the largest dollar decreases. ${ }^{19}$ Overall, consumers of these popular vehicles benefit by an amount between $\$ 100$ and $\$ 150$ dollars. When aggregated benefits across all new vehicle purchasers in 1984, gains to non-minivan purchasers account for almost $43 \%$ of the total consumer benefits.

Table $3 \mathrm{~b}$ presents the compensating variation results for minivan purchasers across the four different demand-side models. Compensating variation is the dollar amount a (former) minivan purchaser would need to be compensated in the equilibrium without minivans to be just indifferent to being in the equilibrium with minivans. The medians,

\footnotetext{
${ }^{18}$ The model is sufficiently flexible to match the new moments; predictions for average family size given minivan and station wagon purchase are 3.85 and 3.19 respectively, and 3.86 and 3.17 from the CEX data. Under the null hypothesis of "compatible", the formal test statistic is distributed chi-squared with 10 degrees of freedom, and the realized value of 8.5 is below the $10 \%$ level-of-significance critical value of 15.98 .

${ }^{19}$ See Table $\mathrm{A}$ in the appendix for more detail on estimated substitution patterns.
} 
means, and the standard deviations of the distribution of compensating variations vary substantially across the demand-side models. The OLS and IV logit models suffer from very inelastic demand curves, as average compensation is $\$ 13,652$ and $\$ 7,414$ respectively on a new vehicle that sold for $\$ 8,722$. Results improve significantly with the move to random coefficients using just market-level data, but the average compensation still appears to be quite high $(\$ 3,171)$ relative to the new-product introductory price. The random coefficients model augmented with data on consumer observables yields a prediction of $\$ 1,247$ for average compensation, the most plausible of the four.

In order to gain a better understanding of what lies behind these differences, Chart 1 plots the distribution of compensating variations for the IV logit model, the random coefficients approach without micro data, and the full model. Here a story of "extremetaste" consumers is quite evident, as the top two histograms illustrate the dominant role played by the i.i.d. logit error in explaining minivan purchase. In the IV logit case, over $40 \%$ of minivan purchasers would willingly pay an additional $\$ 8,722$ (the minivan's introductory price) to retain the right to purchase the minivan, and an extreme $10 \%$ would offer at least $\$ 20,000$. While the situation improves with the random coefficients (the second histogram), there are still many consumers that can find no close substitute in the new vehicle market and would still willingly pay thousands of dollars to retain the minivan. It is not until the micro data is brought to the random coefficients framework (the third histogram) that substitution patterns suggest minivan purchasers are able to find compensation from other vehicles' observed characteristics. Additionally, the extra information appears to be quite important for accurately identifying the marginal utility of income terms; the full model is the only model that reasonably predicts average income conditional on purchase (see Table 2a.) I now turn to changes on the supply side.

\subsection{Markups, Producer Surplus, and Profit Dissipation}

In this section I summarize markups for family vehicles and the entire new vehicle market over the first few years of the minivan introduction. I also explore how these markups differ across the different demand side models, how variable profits changed as a result of the introduction, and how fast competitors cannibalized Chrysler's profits from its minivan.

Table 4a, which reports some figures on the distribution of markups under each of the 
four demand systems, makes it clear that unreasonable demand side elasticities contaminate the the supply side results. In the case of the OLS and IV logit, markups average $\$ 13,904$ and $\$ 7,551$ over the sample period, so estimated marginal costs are negative for $73 \%$ and $22 \%$ of vehicles respectively. Of some interest is the fact that the difference in the estimated markups between the OLS and IV logit frameworks arises almost entirely from the difference in estimates of $\alpha$ (price-sensitivity) due to instrumenting; the ratio of the coefficients, $0.13 / 0.07$, is almost exactly equal to the ratio of average markups, or $\$ 13,904 / \$ 7,551$.

Markups from the full model (column 1) and the random coefficients model restricted to market-level data (column 2) are all positive. The average markup from the model without micro data is about twice that of the average markup when micro data is added to the framework ( $40 \%$ vs. $17 \%$ ), which is well within the realm of realistic for the automobile market. ${ }^{20}$ However, some markups without micro data reflect the less elastic demand curves than those from the full model; at least $10 \%$ of the vehicles have markups great than $62 \%$.

Table $4 \mathrm{~b}$ reports the average (sales-weighted) prices and markups/price for family vehicles and for all other vehicles from 1983-1987. Minivans enjoy consistently larger markups than station wagons, sport-utility vehicles, and other new vehicles. Station wagon markups are $2 \%$ to $3 \%$ lower on average than minivan markups, and consistently fall below the market average. Markups also appear to generally fall over this time period in the new vehicle market, primarily because it becomes increasingly crowded as the number of models climbs from 157 in 1983 to 198 in 1987.

Changes in Chrysler's, Ford's and GM's total variable profits and in industry profits due to the introduction of the minivan are reported in Table 4c. Chrysler benefits signif-

\footnotetext{
${ }^{20}$ Two estimates of markups from the same time period come from BLP and Goldberg (1995). BLP use market-level data from 1971-1990 on the U.S. passenger car market (i.e. no minivans, sport-utilities, or vans). Their random coefficients model (in which they instrument) yields ranges of markups depending upon the cost and demand side specification that range from as small as $15 \%$ to $25 \%$ to as large as $30 \%$ to $40 \%$ (their analysis reports seven different cost side specifications.) Goldberg (1995) uses a nested-logit framework with the same market-level data as BLP (only using 1983-87) and combines this data with consumer-level information from the CEX. She treats prices as exogenous and finds an average markup of $38 \%$, with a range from $14 \%$ to $61 \%$. She also reports estimates from a number of other different sources, including Annual Survey of Manufacturers, and Consumer Reports, both of which suggest an average markup between $15 \%$ and $25 \%$.
} 
icantly from introducing the minivan, as variable profits increase by $\$ 202$ million (14\%) in its first year, relative to what profits would have been without the introduction. Sales and markups continue to grow over the next few years, partly because Chrysler continues to innovate on its original innovation, and partly because consumers learn about the new product. By the end of 1987, Chrysler's minivans had generated almost $\$ 1.5$ billion in profits, well-exceeding the estimated $\$ 700$ million spent on the cost of development, and this appears to have been only the beginning for their minivan's success. ${ }^{21}$

Ford and GM are both hurt by Chrysler's innovation. In percentage terms, they lose between $1 \%$ and $2 \%$ annually, which works out to hundreds of millions for GM. Both were quick to respond to Chrysler, introducing their own versions of minivans, although they handled like trucks and had the design of a down-sized full-size van. Table $4 \mathrm{~d}$ reports a measure of the success these imitations had in dissipating Chrysler's private returns by computing Chrysler's hypothetical profits without Ford and GM minivans. These profits are then compared to the profits that actually obtain. Over four years GM and Ford dissipated approximately $\$ 126$ million dollars, which amounts to approximately a loss in sales of 76,000 minivans. While significant, they are not enormous, as Chrysler appears to have created a unique and different product.

\subsection{Total Welfare Change: 1984-88}

Table 5 summarizes changes in consumer and producer welfare across the industry after the introduction of the minivan for the years 1984-88. Consumers benefit significantly, gaining a new product for which some households, especially those with large families, have strong taste. Additionally, non-minivan consumers reap the benefits of price competition, obtaining almost half of the overall returns to this new innovation. For example, of the $\$ 367$ million in consumer gains for $1984, \$ 210$ million accrued to minivan buyers, while $\$ 157$ million went to non-minivan buyers. It also appears that the industry ex post would have been willing to pay Chrysler to not produce the minivan, as total producer surplus

\footnotetext{
${ }^{21}$ Information on total cost of development is difficult to locate. The $\$ 700$ million figure was reported in the March 21, 1983 issue of Time magazine. Other figures include an estimate from the November 14, 1983 issue of Fortune, which reported a $\$ 400$ million cost of retooling at the first minivan plant (a lower bound on total development costs.) Chrysler's total planned investment in new products was reported to be $\$ 1.5$ billion in 1983 (Ward's Automotive, 1983). Of course, some of the initial design of the minivan had been completed by DeLaRussa while he worked at Ford in the 1970s.
} 
for the industry falls slightly in 1984 and 1985. Finally, total welfare change over the first five years is about $\$ 2.9$ billion dollars, of which $\$ 2.8$ billion is from consumer surplus, suggesting benefits to consumers of this new product introduction swamped both the costs to society of producing the vehicle and the private returns the innovator obtained.

\subsection{Specification and Robustness Checks}

In this subsection I provide specification/robustness checks. I test whether the model appears to be consistent with the additional micro moments. I explore whether compensating variation results are sensitive to different choice sets over time and to different assumptions about price changes. I report the equivalent of Table 5, which summarizes the change in welfare, using the observed (equilibrium) prices with minivans in the market instead of the new predicted prices from the model. Finally, I explore different distributional assumptions for unobserved tastes to see whether the compensating variation numbers are sensitive to them.

Table 6a reports the Consumer Expenditure Survey moments that I ask the model to match. It also reports the model predictions for these moments at the parameter estimates. Overall, the results indicate that the model's parameterization is sufficiently flexible to match the moments. Average family sizes conditional on different vehicle purchases match very closely. The CEX data suggest a point estimate of 3.86 for minivans, while the model yields an estimate of 3.85 , well within the 0.1 standard error from the CEX sampling variance. ${ }^{22}$ Similarly, for station wagons the CEX data yields an average of 3.17 with a standard deviation of 0.17 , while the full model predicts 3.19 . Predictions for probability of being middle aged given family vehicle purchase and probability of new car purchase conditional on income group are also statistically reasonable. Finally, a formal test of differences is not able to reject the null that the two estimates are the same. ${ }^{23}$

Table $6 \mathrm{~b}$ reports results over time from the full model for compensating variation and for substitution patterns within the family vehicle segment. The distribution of compensating variation appears to be stable over changing choice sets and to evaluating compensating variation at either the new equilibrium prices without minivan's in the

\footnotetext{
${ }^{22}$ This standard error ignores the variance from the estimated parameters. Incorporating this variance would only increase the likelihood that I would conclude the model and the CEX data are compatible.

${ }^{23}$ The test statistic is distributed chi-squared with 10 degrees of freedom, and the realized value of 8.5 is below the $10 \%$ level-of-significance critical value of 15.98 .
} 
market, or at the equilibrium prices obtained with minivans in the market (column marked with minivans.) $)^{24}$

The fraction of minivan purchasers substituting to the other kinds of family vehicles is reported at the bottom of table $6 \mathrm{~b}$. Substitution patterns between family vehicles do appear to change over time in a way consistent with anecdotal evidence in the market. One can see that minivan purchasers primarily (31\%) substitute to station wagons in 1984 . By 1997, only $13 \%$ of former minivan purchasers are buying station wagons, as these family vehicles are eclipsed by a new breed of sport-utilities that, similar to minivans, are becoming more family friendly over time.

The overall welfare results using the equilibrium prices when minivans were in the market during 1984-1988 are reported in Table 6c. While these are the equilibrium prices with minivans in the choice set, they provide a useful alternative set of prices which I use to check robustness, and the results are quite similar. ${ }^{25}$

Table 6d presents some robustness results for the distributional assumptions made on the random coefficients associated with the observed product characteristics. I only experiment with different $\chi^{2}$ distributions for idiosyncratic tastes of observed product characteristics because I want to bound tastes from below (so there are not people that infinitely dislike every characteristic.) Four different distributional specifications are reported, including the $\chi^{2}(3)$ and the $\chi^{2}(1)$ distributions, and their truncated counterparts (cut off at 95\%). The improvements over previous approaches appear to be robust to changes in the distributional specifications. However, the non-truncated distributions do produce welfare numbers that are larger than their truncated counterparts, suggesting that the tails of these distributions can still play a role in the welfare measure. Also, the $\chi^{2}(3)$ distribution yields numbers marginally larger that $\chi^{2}(1)$ distribution, perhaps because of the thicker tail this the sum of three squared normal deviates has relative to just one squared normal deviate.

\footnotetext{
${ }^{24}$ I have also estimated the model with the demand side alone, and the consumer surplus numbers that obtain are very similar.

${ }^{25}$ If the choice set from the previous year included exactly the same vehicles up to the minivan, 1983 prices would be the best set of equilibrium prices to use for the counterfactual. Unfortunately, between 1983 and 1984 some vehicles leave the choice set, other new vehicles appear, and some vehicles in the choice set change their characteristics.
} 


\section{Conclusions}

In this paper I report two main findings. One is of methodological importance for the estimation of demand systems in differentiated goods' markets. The second quantifies how the minivan introduction changed consumer and producer welfare in the United States.

I suggest a technique useful for obtaining more precise estimates of demand curves. My recommendation is to supplement market-level data with information matching some important averages of consumers to those of observed product characteristics. Many kinds of observed empirical means can be used to supplement the estimation routine, making the technique useful for a broad range of markets where price and product characteristics data may not be sufficient to precisely identify the relevant substitution patterns. I find the results obtained from using previous methodologies far less plausible both economically and statistically than what I obtain when I use the additional data.

I focus on the quantitative effects of the minivan introduction. The model suggests that consumer benefits swamped both the development costs and the profits obtained by the innovator. Consumer benefits are distributed across households in a non-random way, and almost half of these benefits accrued to new vehicle buyers that were not minivan purchasers, but were purchasing other vehicles with lower prices due to increased competition. On the producer side, the results were mixed. Chrysler obtained large benefits from the minivan introduction, easily recouping its initial development costs. These sales came at the expense of the rest of the industry, especially since Ford and General Motors were unprepared for the minivan innovation and unable to respond quickly with the introduction of a comparable product.

My results support a simple economic story where large improvements in consumers' standard of living arise from competition between firms in a differentiated goods market. These firms ignore the externalities imposed upon one another as they cannibalize each others profits by introducing new and different goods. The new goods that successfully differentiate themselves from existing products frequently yield large profits for the innovator, and even more importantly, can generate benefits for consumers that swamp those accruing to the innovator. 


\section{A Substitution Patterns}

Here I discuss the substitution patterns implied by the parameter estimates. Table A documents the 1984 substitution patterns for four family vehicles and one top-selling inexpensive small sedan. These vehicles are Chrysler's Dodge Caravan minivan, General Motor's Chevrolet Celebrity station wagon (the top-selling station wagon in 1984), Chrysler's full-size Ram B10 van (one of the top-selling three vans), the Chevrolet Blazer K sport utility vehicle (one of the biggest sport utility's of the day), and the Dodge Aries $\mathrm{K}$-car, a small, inexpensive family sedan (to provide some idea of what substitution patterns look like outside the family vehicle segment.) I report the own-price elasticity of each model and their top five substitutes. A number of other vehicles, many of which are in the family vehicle segment, appear in the cross-price elasticity part of table A, and I denote these vehicles as MI (minivan), SW (station wagon), SU (sport-utility), VAN (full-size van), or SS (small sedan.)

The model estimates imply an own-price elasticity of -6.695 for the new Dodge Caravan; a one percent increase in the Dodge Caravan's $\$ 8722$ introduction price (1982-84 dollars) would lead to a $6.7 \%$ fall in demand (ceteris paribus). The model predicts the Caravan's closest substitute to be the Celebrity station wagon (column 2), the top-selling station wagon in 1984. The Celebrity has in turn the Caravan as its closest substitute. ${ }^{26}$ Demand for the Celebrity is more price elastic than demand for the Caravan, probably due to the stiff nature of competition between station wagons, as $18.4 \%$ of the 1984 new vehicle models are in this class. Both the Caravan's and the Celebrity's other top competitors are all mid-size and large station wagons.

The full-size Ram B10 van and General Motor's Blazer K sport utility are reported in columns 3 and 4. Again, the results for these sub-categories appear sensible. They each have at least one representative of the van, sport utility, and station wagon class in their top five substitutes. Chrysler's Ram B10 van has as closest competitors Chevrolet's Sportvan and Ford's Econoline 150 van, which together make up 65\% of the 1984 full-size van market segment. A similar result obtains for the Blazer $\mathrm{K}$, the second biggest sport utility available to consumers in 1984. The model predicts as its closest substitute the Suburban C10, another General Motor's sport utility that has the distinction of being the largest sport utility in the sample from 1984-93. Finally, the Dodge Aries K-car, a

\footnotetext{
${ }^{26}$ This symmetric outcome is not directly imposed by the model.
} 
mid-sized inexpensive (\$6658) family sedan in the crowded family sedan market, has the highest own-price elasticity of the five automobiles surveyed here. This result is consistent with the small sedan segment of the vehicle market; not only is it in one of the market's most crowded segments, but it is also frequented by the most price-sensitive consumers. Again, the model sensibly predicts substitution patterns; the Dodge Aries $\mathrm{K}$ primary substitutes are all other inexpensive small family sedans of the day, including the Ford Escort (\$5616), the (Ford) Mercury Lynx (\$5542), the Chevrolet Celebrity family sedan $(\$ 5988)$, and Chrysler's Dodge Colt $(\$ 5400)$. 


\section{B Computational Issues}

In this section I describe three important computational aspects to the welfare calculations. $^{27}$ First, I show how the delta method is used to compute the variance of the CEX moments. Next, I provide an overview of the minimization algorithm, including a description of the computation of the micro moments implied by any set of parameter values. Finally, I describe the algorithm that is used to locate new equilibrium prices for the different counterfactuals I consider.

\section{B.1 Estimating the Variance of the CEX moments}

I use the delta method to compute the variance-covariance matrix for the CEX moments. This matrix enters both the optimal weighting matrix and the estimates of the standard errors. The need for the delta method arises because the conditions for the conditional moments are not generally satisfied by all $N$ observations in the CEX. ${ }^{28}$ Here I outline this construction for two conditional means from Section 7. The procedure extends directly to additional moments.

I begin by constructing new random variables that yield exactly the same conditional means, but use all $N$ observations from the CEX. Define the vector of indicator random variables $I=\left\{I_{1}, I_{2}, I_{3}, I_{4}\right\}$ as

$$
\begin{aligned}
& I_{1}=\{i \text { purchases new vehicle }\} *\left\{y_{i}<\bar{y}_{1}\right\} \\
& I_{2}=\left\{y_{i}<\bar{y}_{1}\right\} \\
& I_{3}=f s_{i} *\{i \text { purchases minivan }\} \\
& I_{4}=\{i \text { purchases minivan }\}
\end{aligned}
$$

each of which is well-defined for every one of the $N$ observations in the CEX. Next, construct a function of the means of these four random variables that yields the conditional moments of interest. In this case, define $h(\cdot)$ such that

$$
h\left(\bar{I}_{1}, \bar{I}_{2}, \bar{I}_{3}, \bar{I}_{4}\right)=\left(\bar{I}_{1} / \bar{I}_{2}, \bar{I}_{3} / \bar{I}_{4}\right)
$$

and note that $h(\cdot)$ yields the same estimate of the conditional means that would obtain if I computed them in the "usual" way, by first selecting all observations that satisfied the

\footnotetext{
${ }^{27}$ Most other computational aspects are discussed in Berry, Levinsohn, and Pakes (1995).

${ }^{28}$ While not an issue for computing the variance of any particular moment, this complicates the computation of the covariances between conditional moments.
} 
condition and then averaging. Under mild regularity conditions $\sqrt{N}\left(I-\mu_{I}\right) \stackrel{A}{\sim} N(0, V(I))$, so, by the delta method,

$\sqrt{N}\left(\begin{array}{l}\bar{I}_{1} / \bar{I}_{2}-E\left[\{i \text { purchases new vehicle }\} \mid\left\{y_{i}<\bar{y}_{1}\right\}\right] \\ \bar{I}_{3} / \bar{I}_{4}-E\left[f s_{i} \mid\{i \text { purchases minivan }\}\right]\end{array}\right) \stackrel{A}{\sim} N\left(0, \nabla h\left(\mu_{I}\right) V(I) \nabla h\left(\mu_{I}\right)^{\prime}\right)$,

where $\nabla h\left(\mu_{I}\right)$ is the gradient of $h\left(\mu_{I}\right)$. Thus, the CEX variance can be computed with an estimate of $V(I)$ obtained from all $N$ observations, combined with an estimate of the derivative of $h(\cdot)$ obtained using an analytic solution to the gradient and the data.

\section{B.2 Estimating the Parameters}

Using the Nelder-Mead Non-Derivative search algorithm (see Nelder and Mead (1965)), the objective function is evaluated at many different values of $\theta \in \Theta$ until the minimum is located. ${ }^{29}$ The following five steps provide an overview of this iterative process. I describe the first three in detail.

Given a $\theta \in \Theta$ :

1) locate the $\delta^{*}$ that solves $\mathbf{s}=s\left(\delta^{*}, \theta\right)$,

2) compute the micro moments,

3) compute the markups, marginal cost, and the implied BLP moments,

4) use sample moments from (2) and (3) to compute objective function value,

5) perturb $\theta$ using Nelder-Mead and return to 1 until minimum located.

Step 1: Locate the $\delta^{*}$ that solves $\boldsymbol{s}=s\left(\delta^{*}, \theta\right)$

Berry, Levinsohn, and Pakes (1995) design a contraction mapping for locating the $\delta^{*}$ that matches observed to predicted market shares. They prove that the operator

$$
T(\theta)[\delta]=\delta+\ln (\mathbf{s})-\ln (s(\theta, \delta))
$$

is a contraction mapping with modulus less than one for random utility with a logit error. Given $\theta$ and an initial guess for $\delta$, say $\delta^{1}, s\left(\theta, \delta^{1}\right)$ is computed, and, using the operator above, a new $\delta, \delta^{2}=T(\theta)\left[\delta^{1}\right]$ obtains. This process is repeated until the distance between $\delta_{n}$ and $\delta_{n-1}$ is small (the contraction property ensures that this distance can be made as small as desired.)

\footnotetext{
${ }^{29}$ The computational work is done in Gauss and $\mathrm{C}$, with code available on request.
} 
Step 2: Compute the micro moments

For any candidate set of parameter values, the error in any micro moment is computed as the difference between the CEX value of the conditional mean (which is unaffected by the parameter values) and the prediction offered by the model. The prediction from the model is computed using Bayes Rule. I illustrate this computation for average family size given minivan purchase; the other moments are computed in a similar manner.

Average family size conditional on minivan purchase is given by

$$
\sum_{f s=1}^{k} f s \operatorname{Pr}(f s \mid \text { minivan purchase }) .
$$

Thus, its computation requires an estimate of the probabilities associated with family size taking on different values for minivan purchasers. Using Bayes Rule, the conditional probabilities can be rewritten as

$$
\frac{\operatorname{Pr}(\text { minivan purchase } \mid f s) \operatorname{Pr}(f s)}{\operatorname{Pr}(\text { minivan purchase })}
$$

An estimator of the probability of minivan purchase is given by the observed market share of minivans (and is exactly matched by the model because the individual automobile market shares are matched.) An estimate of $\operatorname{Pr}(f s)$ is computed from the CEX. An estimate of the average probability of minivan purchase conditional on family size is obtained in two steps. First, simulate (to integrate out) the unobserved tastes for each family from the CEX sample; this yields a minivan purchase probability for each CEX family. Second, average the purchase probabilities for each family size (i.e. integrate over the observed demographics.) With these three probabilities and (B.2) one can estimate the average family size conditional on minivan purchase from the model. The other micro means are computed in a similar manner.

Step 3: Compute the markups, marginal cost, and the implied BLP moments

Estimates of the markups obtain from simulating the derivatives that enter $\Delta$ (see (5.3)). Marginal cost (mc) is observed price minus estimated markup. Estimates of $\delta^{*}$ and the log of marginal cost are then regressed onto the demand and cost side characteristics. Residuals for each product, $\hat{\xi}_{j}=\delta_{j}^{*}-X_{j} \hat{\beta}_{0}$ and $\hat{\omega}_{j}=\ln \left(\mathrm{mc}_{j}\right)-W_{j} \hat{\gamma}$ are interacted with the instruments to obtain the BLP moments. 


\section{B.3 Solving for New Equilibrium Prices}

The numerical algorithm for locating new equilibrium prices comes from (5.3), the rearranged equilibrium first order conditions. A fixed point of the operator

$$
V[\theta][p]=m c(\theta)+\Delta(\theta, p)^{-1} * s(\theta, p)
$$

is an equilibrium price vector if the second order conditions for a maximum (profit maximization) hold at the fixed point. There is no guarantee that this operator converges to a fixed point if one (or more) exist.

I use the estimated parameters and markups to estimate new equilibrium prices under a counterfactual, so

$$
V[\hat{\theta}][p]=m c(\hat{\theta})+\Delta(\hat{\theta}, p)^{-1} * s(\hat{\theta}, p) .
$$

In practice the initial guess $p=m c(\hat{\theta})$ seemed to work well. After locating a fixed point that satisfies

$$
p^{*}=m c(\hat{\theta})+\Delta\left(\hat{\theta}, p^{*}\right)^{-1} * s\left(\hat{\theta}, p^{*}\right)
$$

and verifying that the second order conditions hold at $p^{*}$, I use these prices and the new implied sales as the equilibrium prices and quantities for the counterfactual (e.g. no minivans.) 


\section{References}

Armknecht, P. (1984): "Quality adjustment in the CPI and methods to improve it," in Proceedings of the Business and Economic Statistics Section, pp. 57-63. American Statistical Association.

Berry, S., J. Levinsohn, And A. Pakes (1993): "Some Applications and Limitations of Recent Advances in Empirical Industrial Organization: Price Indexes and the Analysis of Environmental Change," American Economic Review, 83(2), 240-246. 890.

(1995): “Automobile Prices in Market Equilibrium," Econometrica, 63(4), 841-

— (1998): "Differentiated Products Demand Systems from a Combination of Micro and Macro Data: Autos Again," Working Paper.

BerRY, S. T. (1994): "Estimating discrete-choice models of product differentiation," RAND Journal of Economics, 25(2), 242-262.

Bresnahan, T., AND R. Gordon (eds.) (1997): The economics of new goods. Chicago: University of Chicago Press.

Bresnahan, T., S. Stern, and M. Trajtenberg (1997): "Market Segmentation and the Sources of Rents from Innovation:Personal Computers in the Late 1980s," RAND Journal of Economics, 28, S17-S44.

Bresnahan, T. F. (1986): "Measuring the Spillovers from Technical Advance: Mainframe Computers in Financial Services," American Economic Review, 76(4), 742-755.

Feenstra, R. C. (1988): Empirical Methods for International Trade.Cambridge, MA: MIT Press, chap. 5, pp. 119-140.

Fershtman, C., And N. Gandal (1998): "The Effect of the Arab Boycott on Israel: The Automobile Market," RAND Journal of Economics, 29, 193-214.

Goldberg, P. (1995): "Product Differentiation and Oligopoly in International Markets: the Case of the U.S. Automobile Industry," Econometrica, 63, 891-952. 
Greenstein, S. (1994): "From Super-Minis to Super-Computers: Estimating Surplus in the Computing Market," NBER Working Paper 4899.

Hansen, L. P. (1982): "Large Sample Properties of Generalized Method of Moments Estimators," Econometrica, 50(4), 1029-1054.

Hausman, J. (1998): "Cellular Telephone, New Products and the CPI," mimeo, MIT.

Hausman, J. A. (1997a): Valuation of New Goods Under Perfect and Imperfect Competition, in The Economics of New Goods.Chicago: University of Chicago Press, chap. 5, pp. 209-237.

(1997b): "Valuing the Effects of Regulation on New Services in Telecommunications," in Brookings Papers on Economic Activity, Microeconomics.

Hicks, J. R. (1946): "The Generalized Theory of Consumers' Surplus," Review of Economic Studies, 13.

IACOCCA, L. (1986): Iacocca. Bantam Books.

Imbens, G. W., And T. Lancaster (1994): "Combining Micro and Macro Data in Microeconometric Models," Review of Economic Studies, 61(4), 655-680.

McFadden, D. (1981): Econometric Models of Probabilistic Choice, in Structural Analysis of Discrete Data with Econometric Applications.Cambridge: MIT Press, chap. 5.

Nelder, J., ANd R. Mead (1965): "A Simplex Method for Function Minimization," The Computer Journal, 7, 308-13.

Nevo, A. (1998): "Measuring Market Power in the Ready-To-Eat Cereal Industry," NBER Working Paper No. $638 \%$.

Trajtenberg, M. (1989): "The Welfare Analysis of Product Innovations, with an Application to Computed Tomography Scanners," Journal of Political Economy, 94, 444479.

YATES, B. (1996): The critical path : inventing an automobile and reinventing corporation. Little, Brown. 
TABLE 1a

Average (Sales-Weighted) Characteristics for Selected Vehicle Types, 1981-93

\begin{tabular}{|c|c|c|c|c|c|c|c|}
\hline & \multicolumn{2}{|c|}{$\begin{array}{c}\text { All } \\
\text { Vehicles }\end{array}$} & \multirow[t]{2}{*}{ Minivans } & \multirow[t]{2}{*}{$\begin{array}{c}\text { St. Wagons } \\
\mathrm{p}<\$ 7,7,54\end{array}$} & \multirow[t]{2}{*}{$\begin{array}{l}\text { St. Wagons } \\
\mathrm{p} \geq \$ 7,7,54\end{array}$} & \multirow[t]{2}{*}{$\begin{array}{c}\text { Sport } \\
\text { Utilities }\end{array}$} & \multirow[t]{2}{*}{$\begin{array}{c}\text { Full Size } \\
\text { Vans }\end{array}$} \\
\hline & Mean & StdDev & & & & & \\
\hline Horsepower/Weight & 0.39 & 0.07 & 0.36 & 0.35 & 0.37 & 0.40 & 0.30 \\
\hline Length*Width*Height & 0.71 & 0.13 & 0.87 & 0.60 & 0.78 & 0.83 & 1.13 \\
\hline A/C Standard & 0.27 & 0.44 & 0.78 & 0.00 & 0.16 & 0.56 & 0.37 \\
\hline Miles/Dollar & 24.11 & 6.55 & 22.84 & 26.50 & 22.24 & 20.20 & 17.56 \\
\hline Front Wheel Drive & 0.64 & 0.48 & 0.63 & 0.83 & 0.60 & 0.00 & 0.00 \\
\hline List Price (1982-84 CPI \$) & 9,867 & 4,559 & 10,060 & 6,864 & 10,421 & 10,949 & 10,321 \\
\hline
\end{tabular}

Notes:

1) List price is base model price.

2) Lowest list-price quartile of station wagons separated out from the top $75 \%$.

TABLE 1b

Average Consumer Characteristics for the U.S. and Selected Sub-Populations, 1987-92

\begin{tabular}{|c|c|c|c|c|c|c|c|}
\hline & \multicolumn{2}{|c|}{ U.S. } & \multirow{2}{*}{$\begin{array}{l}\text { New Vehicle } \\
\text { Purchasers }\end{array}$} & \multirow{2}{*}{$\begin{array}{c}\text { Minivan } \\
\text { Purchasers }\end{array}$} & \multirow{2}{*}{$\begin{array}{l}\text { St. Wagon } \\
\text { Purchasers }\end{array}$} & \multirow{2}{*}{$\begin{array}{l}\text { Sport Util } \\
\text { Purchasers }\end{array}$} & \multirow{2}{*}{$\begin{array}{c}\text { FS Van } \\
\text { Purchasers }\end{array}$} \\
\hline & Mean & StdDev & & & & & \\
\hline Income & 23,728 & 21,255 & 36,113 & 39,476 & 40,196 & 41,569 & 31,164 \\
\hline Family Size & 2.58 & 1.53 & 2.87 & 3.86 & 3.17 & 2.97 & 3.47 \\
\hline MidAge & 0.55 & 0.49 & 0.64 & 0.78 & 0.73 & 0.74 & 0.65 \\
\hline
\end{tabular}

Notes:

1) Source is the Consumer Expenditure Survey.

2) Income is measured in 1982-84 CPI adjusted dollars.

3) Family size is number of household members.

4) MidAge is binary variable for head of household age between 30 and 60 inclusive. 
TABLE 1c

Family Vehicle Sales as a Percent of Total Vehicle Sales

U.S. Automobile Market, 1981-1993

\begin{tabular}{lcccccc}
\hline Year & Minivans & $\begin{array}{c}\text { Station } \\
\text { Wagons }\end{array}$ & $\begin{array}{c}\text { Sport } \\
\text { Utilities }\end{array}$ & $\begin{array}{c}\text { Full Size } \\
\text { Vans }\end{array}$ & $\begin{array}{c}\text { Minivans }+ \\
\text { Sta. Wagons }\end{array}$ & $\begin{array}{c}\text { U.S. Auto Sales } \\
\text { Millions }\end{array}$ \\
\hline 1981 & 0.00 & 10.51 & 0.58 & 0.82 & 10.51 & 7.58 \\
1982 & 0.00 & 10.27 & 0.79 & 1.17 & 10.27 & 7.05 \\
1983 & 0.00 & 10.32 & 3.51 & 1.04 & 10.32 & 8.48 \\
1984 & 1.58 & 8.90 & 5.51 & 1.20 & 10.48 & 10.66 \\
1985 & 2.32 & 7.33 & 6.11 & 1.05 & 9.65 & 11.87 \\
1986 & 3.63 & 6.70 & 5.73 & 0.85 & 10.43 & 12.21 \\
1987 & 4.86 & 6.47 & 6.44 & 0.73 & 11.33 & 11.21 \\
1988 & 5.97 & 5.14 & 7.18 & 0.69 & 11.11 & 11.76 \\
1989 & 6.45 & 4.13 & 7.47 & 0.61 & 10.58 & 11.06 \\
1990 & 7.95 & 3.59 & 7.78 & 0.27 & 11.54 & 10.51 \\
1991 & 8.29 & 3.05 & 7.80 & 0.29 & 11.34 & 9.75 \\
1992 & 8.77 & 3.07 & 9.33 & 0.39 & 11.84 & 10.12 \\
1993 & 9.93 & 3.02 & 11.66 & 0.29 & 12.95 & 10.71 \\
\hline
\end{tabular}


TABLE 2a

Parameter Estimates for the Demand Side Equation

\begin{tabular}{|c|c|c|c|c|}
\hline Variable & $\begin{array}{c}\text { Random } \\
\text { Coefficients } \\
\mu_{i j} \neq 0 \\
(1)\end{array}$ & $\begin{array}{c}\text { Random } \\
\text { Coefficients } \\
\mu_{i j} \neq 0 \\
(2)\end{array}$ & $\begin{array}{c}\text { IV } \\
\text { Logit } \\
\mu_{i j}=0 \\
(3)\end{array}$ & $\begin{array}{c}\text { OLS } \\
\text { Logit } \\
\mu_{i j}=0 \\
(4)\end{array}$ \\
\hline & \multicolumn{4}{|c|}{ Base coefficients ( $\beta_{0}$ 's) } \\
\hline Constant & $\begin{array}{l}-15.67 \\
\quad(4.39)^{* *}\end{array}$ & $\begin{array}{l}-12.74 \\
(5.65)^{* *}\end{array}$ & $\begin{array}{l}-10.04 \\
(0.34)^{* *}\end{array}$ & $\begin{array}{l}-10.03 \\
(0.32)^{* *}\end{array}$ \\
\hline Horsepower/Weight & $\begin{array}{c}-2.83 \\
(8.16)\end{array}$ & $\begin{array}{c}3.40 \\
(39.79)\end{array}$ & $\begin{array}{l}3.78 \\
(0.44)^{* *}\end{array}$ & $\begin{array}{l}1.48 \\
(0.34)^{* *}\end{array}$ \\
\hline Size & $\begin{array}{c}4.80 \\
(3.57)^{*}\end{array}$ & $\begin{array}{c}4.60 \\
(24.64)\end{array}$ & $\begin{array}{c}3.25 \\
(0.27)^{* *}\end{array}$ & $\begin{array}{c}3.17 \\
(0.26)^{* *}\end{array}$ \\
\hline Air Cond. Standard & $\begin{array}{c}3.88 \\
(2.21)^{*}\end{array}$ & $\begin{array}{c}-1.97 \\
(2.23)\end{array}$ & $\begin{array}{c}0.21 \\
(0.08)^{* *}\end{array}$ & $\begin{array}{l}-0.20 \\
(0.06)^{* *}\end{array}$ \\
\hline Miles/Dollar & $\begin{array}{l}-15.79 \\
\quad(0.87)^{* *}\end{array}$ & $\begin{array}{c}-0.54 \\
(3.40)\end{array}$ & $\begin{array}{c}0.05 \\
(0.07)\end{array}$ & $\begin{array}{c}0.18 \\
(0.06)^{* *}\end{array}$ \\
\hline Front Wheel Drive & $\begin{array}{l}-12.32 \\
\quad(2.36)^{* *}\end{array}$ & $\begin{array}{c}-5.24 \\
(3.09)\end{array}$ & $\begin{array}{c}0.15 \\
(0.06)^{* *}\end{array}$ & $\begin{array}{c}0.32 \\
(0.05)^{* *}\end{array}$ \\
\hline Minivan & $\begin{array}{l}-5.65 \\
(0.68)^{* *}\end{array}$ & $\begin{array}{c}-4.34 \\
(13.16)\end{array}$ & $\begin{array}{c}-0.10 \\
(0.15)\end{array}$ & $\begin{array}{c}0.09 \\
(0.14)\end{array}$ \\
\hline Station Wagon & $\begin{array}{l}-1.31 \\
(0.36)^{* *}\end{array}$ & $\begin{array}{c}-20.52 \\
(36.17)\end{array}$ & $\begin{array}{l}-1.12 \\
(0.07)^{* *}\end{array}$ & $\begin{array}{l}-1.12 \\
(0.06)^{* *}\end{array}$ \\
\hline Sport Utility & $\begin{array}{l}-4.38 \\
(0.41)^{* *}\end{array}$ & $\begin{array}{c}-3.10 \\
(10.76)\end{array}$ & $\begin{array}{l}-0.61 \\
(0.10)^{* *}\end{array}$ & $\begin{array}{l}-0.41 \\
(0.09)^{* *}\end{array}$ \\
\hline Full Size Van & $\begin{array}{l}-5.26 \\
(1.30)^{* *}\end{array}$ & $\begin{array}{c}-28.54 \\
(235.51)\end{array}$ & $\begin{array}{l}-1.89 \\
(0.17)^{* *}\end{array}$ & $\begin{array}{l}-1.73 \\
(0.16)^{* *}\end{array}$ \\
\hline \% Change GNP & $\begin{array}{l}0.24 \\
(0.02)^{* *}\end{array}$ & $\begin{array}{l}0.08 \\
(0.02)^{* *}\end{array}$ & $\begin{array}{l}0.03 \\
(0.01)^{* *}\end{array}$ & $\begin{array}{c}0.03 \\
(0.01)^{* *}\end{array}$ \\
\hline & \multicolumn{4}{|c|}{ Term on Price $\left(\alpha^{\prime} s\right)$} \\
\hline$\alpha_{1}$ & $\begin{array}{l}7.52 \\
(1.24)^{* *}\end{array}$ & $\begin{array}{c}4.92 \\
(9.78)\end{array}$ & $\begin{array}{l}0.13 \\
(0.01)^{* *}\end{array}$ & $\begin{array}{c}0.07 \\
(0.01)^{* *}\end{array}$ \\
\hline$\alpha_{2}$ & $\begin{array}{l}31.13 \\
(4.07)^{* *}\end{array}$ & $\begin{array}{c}11.89 \\
(21.41)\end{array}$ & & \\
\hline$\alpha_{3}$ & $\begin{array}{l}34.49 \\
(2.56)^{* *}\end{array}$ & $\begin{array}{l}37.92 \\
(18.64)^{* *}\end{array}$ & & \\
\hline Uses CEX (Micro) Data & YES & NO & NO & NO \\
\hline
\end{tabular}

Notes:

Standard errors in parentheses.

* - t-statistic $>1$

$* *$ - t-statistic $>2$

Quadratic time trend included in all specifications.

$\mu_{i j} \neq 0$ - heterogeneity in taste related to observed characteristics permitted. 
TABLE 2a (cont.)

Random Coefficient Parameter Estimates

Random Coefficients ( $\gamma$ 's)

\begin{tabular}{lcc}
\hline \multirow{2}{*}{ Variable } & \multicolumn{2}{c}{ Random Coefficients $\left(\gamma^{\prime}\right.$ s $)$} \\
\cline { 2 - 3 } & Micro Data & No Micro Data \\
\hline \multirow{2}{*}{ Constant } & $(1)$ & $(2)$ \\
Horsepower/Weight & 3.23 & 1.46 \\
& $(0.72)^{* *}$ & $(0.87)^{*}$ \\
Size & 4.43 & 0.10 \\
& $(1.60)^{* *}$ & $(14.15)$ \\
A/C Standard & 0.46 & 0.14 \\
& $(1.07)$ & $(8.60)$ \\
Miles/Dollar & 0.01 & 0.95 \\
Front Wheel Drive & $(0.78)$ & $(0.55)^{*}$ \\
& 2.58 & 0.04 \\
$\gamma_{m i}$ & $(0.14)^{* *}$ & $(1.22)$ \\
& 4.42 & 1.61 \\
$\gamma_{s w}$ & $(0.79)^{* *}$ & $(0.78)^{* *}$ \\
& 0.57 & 0.97 \\
$\gamma_{s u}$ & $(0.10)^{* *}$ & $(2.62)$ \\
& 0.28 & 3.43 \\
$\gamma_{p v}$ & $(0.09)^{* *}$ & $(5.39)$ \\
& 0.31 & 0.59 \\
& $(0.09)^{* *}$ & $(2.84)$ \\
& 0.42 & 4.24 \\
& $(0.21)^{* *}$ & $(32.23)$ \\
\hline
\end{tabular}

Notes:

Standard errors in parentheses.

$*$ t-statistic $>1$

$* *$ - t-statistic $>2$

Quadratic time trend included in all specifications.

$\mu_{i j} \neq 0$ - heterogeneity in taste related to observed characteristics permitted. 
TABLE $2 \mathrm{~b}$

Parameter Estimates for the Cost Side

\begin{tabular}{lcc}
\hline & $\begin{array}{c}\text { Parameter } \\
\text { Estimate }\end{array}$ & $\begin{array}{c}\text { Standard } \\
\text { Error }\end{array}$ \\
& & \\
\hline Constant & 1.50 & 0.08 \\
$\ln ($ HorsePower $/$ Weight $)$ & 0.84 & 0.03 \\
$\ln ($ Weight $)$ & 1.28 & 0.04 \\
$\ln (M P G)$ & 0.23 & 0.04 \\
A/C Standard & 0.24 & 0.01 \\
Front Wheel Drive & 0.01 & 0.01 \\
Trend & -0.01 & 0.01 \\
Japan & 0.12 & 0.01 \\
Japan*Trend & -0.01 & 0.01 \\
Europe & 0.47 & 0.03 \\
Europe*Trend & -0.01 & 0.01 \\
$\ln (q)$ & -0.05 & 0.01 \\
\hline
\end{tabular}


TABLE 3a

Equilibrium Prices With and Without the Minivan, 1984

1982-84 CPI Adjusted \$

\begin{tabular}{lrrrr}
\hline & \multicolumn{2}{c}{ Price: } & & \\
& With & Without & \\
& Minivan & Minivan & \multirow{2}{*}{$\Delta$ Price } & \multirow{2}{*}{ Price } \\
\cline { 2 - 4 } & & & \\
Largest Price Decreases On Entry: & & & & \\
GM Oldsmobile Toronado LS & 15,502 & 15,643 & -141 & 0.90 \\
GM Buick Riviera LS & 15,379 & 15,519 & -139 & 0.89 \\
GM Buick Electra LS & 12,843 & 12,978 & -135 & 1.04 \\
GM Chevrolet Celebrity SW & 8,304 & 8,431 & -127 & 1.51 \\
Ford Cadillac Eldorado LS & 19,578 & 19,704 & -126 & 0.64 \\
Ford Cadillac Seville LS & 21,625 & 21,749 & -125 & 0.57 \\
GM Pontaic 6000 SW & 9,273 & 9,397 & -123 & 1.31 \\
GM Oldsmobile Ciera SW & 9,591 & 9,714 & -123 & 1.27 \\
GM Buick Century SW & 8,935 & 9,056 & -121 & 1.34 \\
GM Oldsmobile Firenza SW & 7,595 & 7,699 & -104 & 1.35 \\
& & & & \\
Largest Price Increases On Entry: & & & & \\
Chrysler LeBaron SW & 9,869 & 9,572 & 297 & 3.10 \\
Volkswagen Quattro SW & 13,263 & 13,079 & 184 & 1.41 \\
Chrysler (Dodge) Aries K SW & 7,829 & 7,659 & 170 & 2.22 \\
AMC Eagle SW & 10,178 & 10,069 & 109 & 1.08 \\
\hline
\end{tabular}

Notes:

1) Vehicle codes:

LS - Large Sedan

SW - Station Wagon

2) Bertrand-Nash pricing with random coefficients does not a priori determine signs of firm-specific price changes. 
TABLE $3 b$

Average Compensating Variation Conditional on Minivan Purchase, 1984 1982-84 CPI Adjusted Dollars

\begin{tabular}{lcccc}
\hline & $\begin{array}{c}\text { Random } \\
\text { Coefficients } \\
\mu_{i j} \neq 0\end{array}$ & $\begin{array}{c}\text { Random } \\
\text { Coefficients } \\
\mu_{i j} \neq 0\end{array}$ & $\begin{array}{c}\text { IV } \\
\text { Logit } \\
\mu_{i j}=0\end{array}$ & $\begin{array}{c}\text { OLS } \\
\text { Logit } \\
\mu_{i j}=0\end{array}$ \\
& $(1)$ & $(2)$ & $(3)$ & $(4)$ \\
\cline { 2 - 5 } & & & & \\
Compensating Variation: & 783 & 1,217 & 5,130 & 9,573 \\
$\quad$ Median & 1,247 & 3,171 & 7,414 & 13,652 \\
Mean & 1,524 & 7,790 & 7,448 & 13,494 \\
Std. Dev. & & & & \\
& & & & \\
Income of Minivan Purchasers: & 36,091 & 99,018 & 23,728 & 23,728 \\
Mean & 22,902 & 184,057 & 21,255 & 21,255 \\
Std. Dev. & & & & \\
CEX (Micro) Data & YES & NO & NO & NO \\
\hline
\end{tabular}

Notes:

1) $\mu_{i j} \neq 0$ indicates heterogeneity in taste permitted for observed characteristics.

2) Compensating variation evaluated at equilibrium prices without minivans. 
TABLE 4a

Implied Markups Derived From Demand-Side Estimates and Bertrand-Nash Pricing Assumption, 1981-1993 (2407 models)

\begin{tabular}{|c|c|c|c|c|c|c|}
\hline \multirow[b]{3}{*}{ Statistic } & & & \multicolumn{3}{|c|}{ \$ and \% Markups Using: } & \multirow{3}{*}{$\begin{array}{c}\text { OLS } \\
\text { Logit } \\
\mu_{i j}=0 \\
\$\end{array}$} \\
\hline & \multicolumn{2}{|c|}{$\begin{array}{c}\text { Random } \\
\text { Coefficients } \\
\mu_{i j} \neq 0\end{array}$} & \multicolumn{2}{|c|}{$\begin{array}{c}\text { Random } \\
\text { Coefficients } \\
\mu_{i j} \neq 0\end{array}$} & \multirow{2}{*}{$\begin{array}{c}\text { IV } \\
\text { Logit } \\
\mu_{i j}=0\end{array}$} & \\
\hline & $\$$ & $\%$ & $\$$ & $\%$ & & \\
\hline Median & 1,439 & $15.0 \%$ & 2,593 & $36.7 \%$ & 7,513 & 13,834 \\
\hline Mean & 1,753 & $16.7 \%$ & 4,017 & $40.7 \%$ & 7,551 & 13,904 \\
\hline $10 \%$ & 819 & $11.2 \%$ & 1,628 & $27.8 \%$ & 7,413 & 13,647 \\
\hline $90 \%$ & 2,856 & $24.8 \%$ & 8,357 & $62.6 \%$ & 7,765 & 14,297 \\
\hline Standard Deviation & 1,229 & $6.2 \%$ & 4,089 & $14.0 \%$ & 140 & 257 \\
\hline \multicolumn{7}{|l|}{$\%$ of Estimated Marginal } \\
\hline CEX (Micro) Data & \multicolumn{2}{|c|}{ YES } & \multicolumn{2}{|c|}{ NO } & NO & $\mathrm{NO}$ \\
\hline
\end{tabular}

Notes:

1) $\mu_{i j} \neq 0$ indicates heterogeneity in taste permitted for observed characteristics.

2) $\%$ markups, or markups/price, are not reported for IV and OLS logit because the estimated marginal cost is negative for many vehicles.

TABLE $4 \mathrm{~b}$

Average (Sales-Weighted) Markup/Price and Price, 1983-1987

\begin{tabular}{lcccccccc}
\hline & \multicolumn{2}{c}{ Minivans } & \multicolumn{2}{c}{$\begin{array}{c}\text { Station } \\
\text { Wagons }\end{array}$} & \multicolumn{2}{c}{$\begin{array}{c}\text { Sport-Utility } \\
\text { Vehicles }\end{array}$} & \multicolumn{2}{c}{$\begin{array}{c}\text { All Other } \\
\text { Vehicles }\end{array}$} \\
\cline { 2 - 9 } Year & $\%$ & $\$$ & $\%$ & $\$$ & $\%$ & $\$$ & $\%$ & $\$$ \\
\hline 1983 & - & - & $18.27 \%$ & 8,230 & $17.28 \%$ & 9,715 & $18.85 \%$ & 9,059 \\
1984 & $19.19 \%$ & 8,722 & $17.83 \%$ & 8,400 & $17.07 \%$ & 9,952 & $17.72 \%$ & 9,085 \\
1985 & $19.43 \%$ & 8,655 & $16.81 \%$ & 8,412 & $16.51 \%$ & 9,904 & $17.12 \%$ & 9,101 \\
1986 & $17.33 \%$ & 8,898 & $15.82 \%$ & 9,164 & $15.41 \%$ & 10,115 & $16.43 \%$ & 9,480 \\
1987 & $16.31 \%$ & 9,527 & $13.86 \%$ & 9,620 & $14.06 \%$ & 11,123 & $14.79 \%$ & 10,053 \\
\hline
\end{tabular}

Note. - Dollars are 1982-84 CPI adjusted. 
TABLE $4 \mathrm{c}$

Change in Industry and Big Three Total Variable Profits

With the Advent of Minivans

\begin{tabular}{|c|c|c|c|c|c|c|c|}
\hline \multirow[b]{2}{*}{ Year } & \multirow[t]{2}{*}{ Industry } & \multicolumn{2}{|c|}{ Chrysler } & \multicolumn{2}{|c|}{ Ford } & \multicolumn{2}{|c|}{ GM } \\
\hline & & \$Millions & $\%$ & \$Millions & $\%$ & \$Millions & $\%$ \\
\hline 1984 & $-0.21 \%$ & 202.5 & 14.38 & -31.8 & -1.16 & -155.8 & -1.50 \\
\hline 1985 & $-0.13 \%$ & 259.1 & 13.99 & -37.4 & -1.29 & -171.0 & -1.63 \\
\hline 1986 & $0.14 \%$ & 201.1 & 12.42 & 54.7 & 1.84 & -119.9 & -1.09 \\
\hline 1987 & $0.17 \%$ & 346.1 & 23.27 & -22.8 & -0.66 & -174.5 & -2.14 \\
\hline 1988 & $0.65 \%$ & 504.1 & 32.50 & -24.7 & -0.70 & -235.4 & -2.90 \\
\hline
\end{tabular}

TABLE 4d

Chrysler's Profit Dissipation With Entry

Ford, GM Minivans

\begin{tabular}{lcc}
\hline & \multicolumn{2}{c}{ Change In Total Variable Profits } \\
\cline { 2 - 3 } Year & \$Millions & $\%$ \\
\hline 1985 & -6.06 & -0.16 \\
1986 & -22.72 & -1.99 \\
1987 & -42.35 & -2.25 \\
1988 & -55.68 & -2.63 \\
\hline
\end{tabular}


TABLE 5

The Change In U.S. Welfare From the Minivan Innovation, 1984-1988

\begin{tabular}{lccc}
\hline & $\begin{array}{c}\text { Compensating } \\
\text { Variation }\end{array}$ & $\begin{array}{c}\text { Change in } \\
\text { Producer Profits }\end{array}$ & $\begin{array}{c}\text { Welfare } \\
\text { Change }\end{array}$ \\
\cline { 2 - 4 } Year & \$Millions & \$Millions & \$Millions \\
\hline 1984 & 367.29 & -36.68 & 330.61 \\
1985 & 625.04 & -25.07 & 599.97 \\
1986 & 439.93 & 27.30 & 467.23 \\
1987 & 596.59 & 29.75 & 626.34 \\
1988 & 775.70 & 110.24 & 885.94 \\
\hline Total & 2804.55 & 105.54 & 2910.09 \\
\hline Note. - Computations done using 1982-84 CPI Adjusted Dollars.
\end{tabular}




\section{TABLE 6a}

Micro Moments from the Consumer Expenditure Survey and Equivalent Predictions from the Full Model

\begin{tabular}{|c|c|c|}
\hline & CEX (StdErr) $)^{1}$ & $\operatorname{Model}(\hat{\theta})^{2}$ \\
\hline \multicolumn{3}{|c|}{ Average Family Size, Given Purchase of: } \\
\hline Minivan & $3.86(0.10)$ & 3.85 \\
\hline Station Wagon & $3.17(0.17)$ & 3.19 \\
\hline Sport-Utility & $2.97(0.12)$ & 3.02 \\
\hline Full-Size Van & $3.47(0.36)$ & 3.44 \\
\hline \multicolumn{3}{|c|}{ Pr(Middle Age $)^{3}$, Given Purchase of: } \\
\hline Minivan & $78.3 \%(3.7 \%)$ & $75.0 \%$ \\
\hline Station Wagon & $73.0 \%(5.5 \%)$ & $67.5 \%$ \\
\hline Sport-Utility & $74.0 \%(3.8 \%)$ & $66.3 \%$ \\
\hline Full-Size Van & $65.2 \%(9.9 \%)$ & $72.5 \%$ \\
\hline \multicolumn{3}{|c|}{$\operatorname{Pr}$ (purchase new car|income tercile): } \\
\hline Middle & $7.94 \%(0.27 \%)$ & $8.07 \%$ \\
\hline High & $15.81 \%(0.37 \%)$ & $15.96 \%$ \\
\hline
\end{tabular}

Notes:

1) Standard error on the Consumer Expenditure Survey reflects sampling variance associated with these moments (accounted for in estimation procedure.)

2) Predicted values for moments evaluated at parameter estimates.

3) Middle age is a binary variable for head of household age between 30 and 60 . 


\section{TABLE $6 \mathrm{~b}$}

Compensating Variation and Substitution Patterns Across Time 1982-84 CPI Adjusted Dollars

\begin{tabular}{lrrrr} 
& \multicolumn{4}{c}{ Year } \\
& 1984 & 1985 & 1987 & 1989 \\
\cline { 2 - 5 } & & & & \\
Compensating Variation (New Prices): & 1,247 & 1,152 & 1,094 & 1,133 \\
$\quad$ Mean & 1,524 & 1,341 & 1,385 & 1,394 \\
Std. Dev. & & & & \\
& & & & \\
Compensating Variation (Old Prices): & 1,221 & 1,181 & 1,099 & 1,086 \\
$\quad$ Mean & 1,472 & 1,316 & 1,491 & 1,200 \\
Std. Dev. & & & & \\
& & & & \\
Minivan Purchasers Substituting To: & $31.1 \%$ & $20.8 \%$ & $18.0 \%$ & $13.3 \%$ \\
$\quad$ Station Wagon & $1.6 \%$ & $5.9 \%$ & $15.2 \%$ & $19.6 \%$ \\
$\quad$ Sport Utility & $1.0 \%$ & $1.3 \%$ & $1.9 \%$ & $3.1 \%$ \\
$\quad$ Full Size Passenger Van & & & & \\
\hline
\end{tabular}

Notes:

1) New and old prices are equilibrium prices with and without minivans respectively.

2) Substitution patterns evaluated at equilibrium prices without minivans. 
TABLE 6c

The Change In U.S. Welfare From the Minivan Innovation, 1984-1989 Equilibrium Prices With Minivans

\begin{tabular}{lccc}
\hline & $\begin{array}{c}\text { Compensating } \\
\text { Variation }\end{array}$ & $\begin{array}{c}\text { Change in } \\
\text { Producer Profits }\end{array}$ & $\begin{array}{c}\text { Welfare } \\
\text { Change }\end{array}$ \\
\cline { 2 - 4 } Year & \$Millions & \$Millions & \$Millions \\
\hline 1984 & 307.66 & -7.85 & 299.81 \\
1985 & 600.28 & 9.37 & 609.65 \\
1986 & 554.29 & 40.76 & 595.05 \\
1987 & 736.45 & 71.60 & 808.05 \\
1988 & 1000.01 & 146.33 & 1146.34 \\
\hline Total & 3198.69 & 260.21 & 3458.90 \\
\hline Note. - Computations done at equilibrium prices when minivans were in &
\end{tabular}

TABLE 6d

Robustness Across Distributional Assumptions For Random Coefficients 1982-84 CPI Adjusted Dollars

\begin{tabular}{lrrrr}
\hline & $\begin{array}{c}\chi^{2}(3) \\
95 \%\end{array}$ & $\begin{array}{c}\chi^{2}(1) \\
95 \%\end{array}$ & $\begin{array}{c}\chi^{2}(3) \\
\mathrm{NT}\end{array}$ & $\begin{array}{c}\chi^{2}(1) \\
\mathrm{NT}\end{array}$ \\
\cline { 2 - 5 } & & & & \\
Compensating Variation: & & & & \\
Median & 783 & 667 & 1,249 & 899 \\
Mean & 1,247 & 1,125 & 2,026 & 1,658 \\
Std. Dev. & 1,524 & 1,616 & 2,496 & 2,610 \\
\hline
\end{tabular}

Notes:

1) $95 \%$ - Distribution truncated at 95th percentile

2) NT - No truncation of distribution 


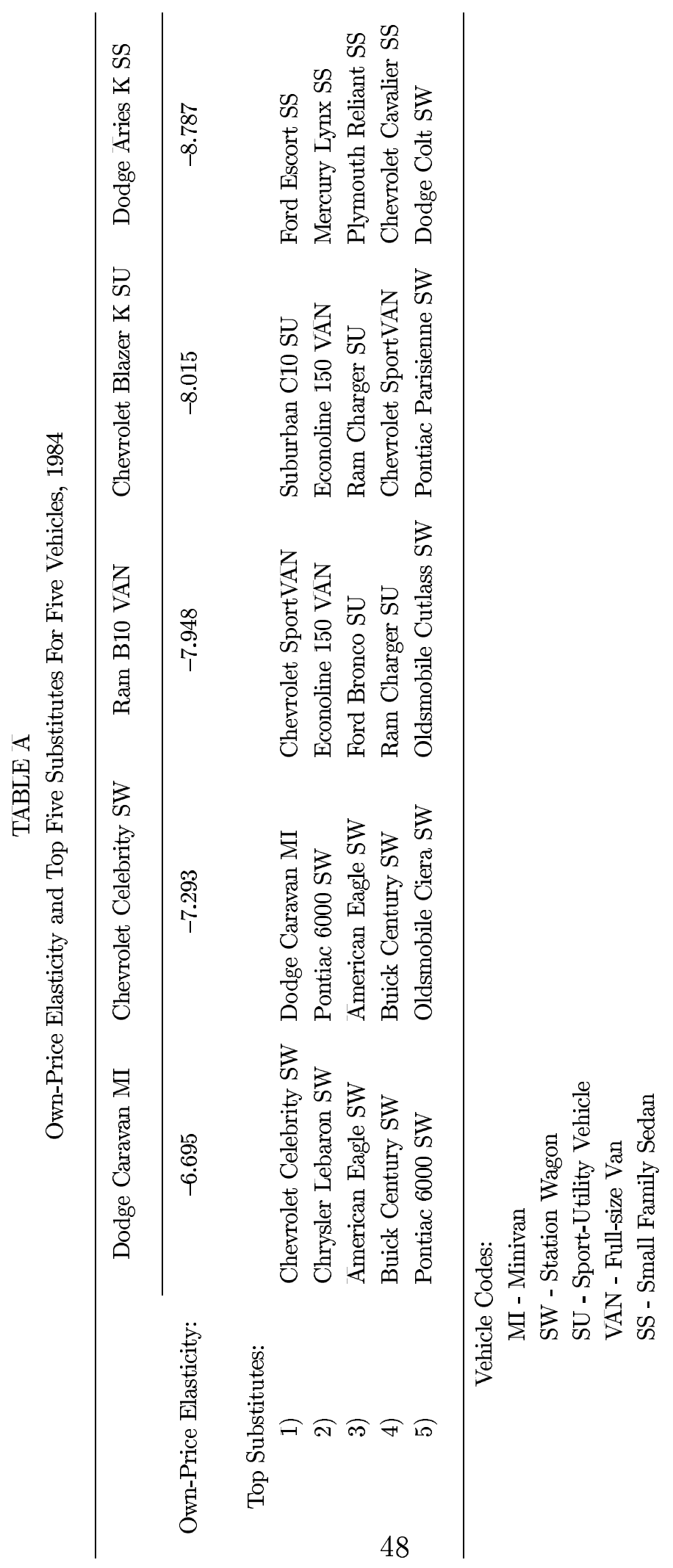



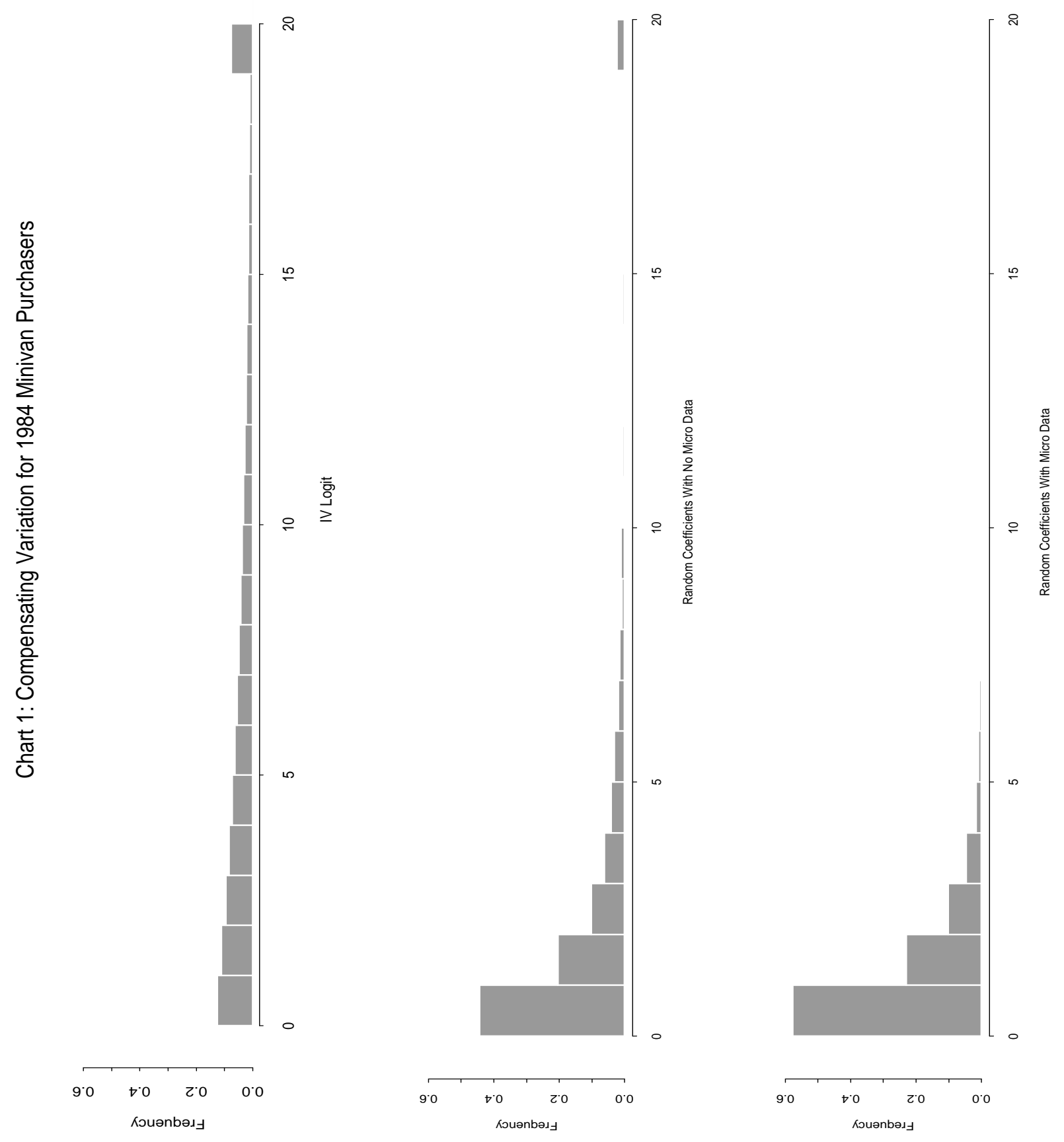


\section{Variation in Choice Sets and Identification}

CHOICE SET 1: $\quad$ All other

characteristics

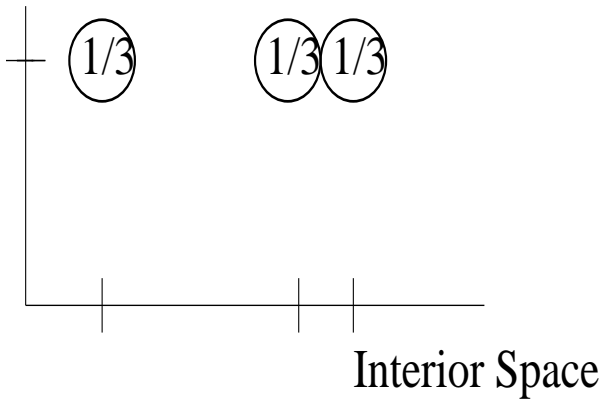

\section{CHOICE SET 2:}

Case 1 -- evidence for taste heterogeneity:

All other

characteristics

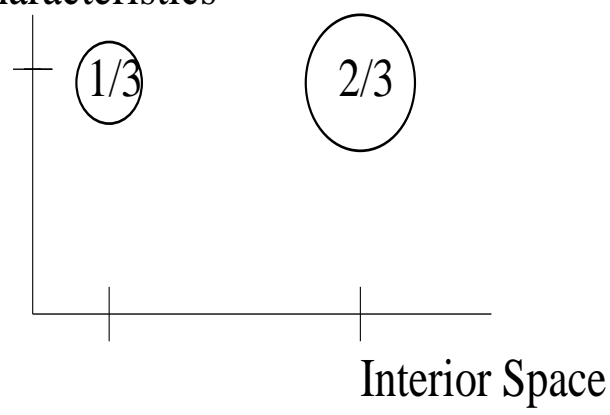

Case 2 -- no evidence for taste heterogeneity:

All other

characteristics

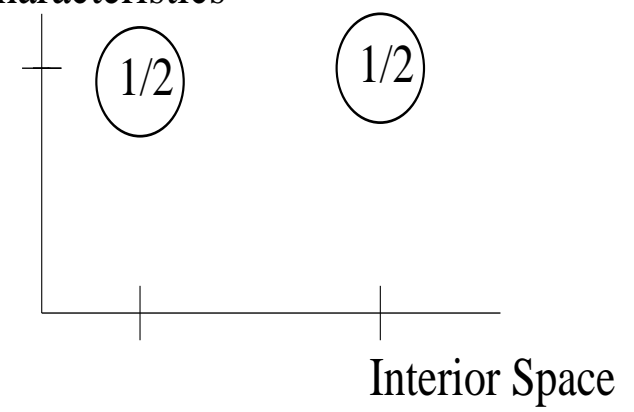

Figure 1 